\title{
Transcriptome analysis of highly purified mouse spermatogenic cell populations: gene expression signatures switch from meiotic-to postmeiotic-related processes at pachytene stage
}

Irene da Cruz ${ }^{1,2+}{ }^{2}$, Rosana Rodríguez-Casuriaga ${ }^{2+}$, Federico F. Santiñaque ${ }^{3}$, Joaquina Farías ${ }^{4}$, Gianni Curti $^{2}$, Carlos A. Capoano ${ }^{2}$, Gustavo A. Folle ${ }^{3,5}$, Ricardo Benavente ${ }^{6}$, José Roberto Sotelo-Silveira ${ }^{1,7^{*}}$ and Adriana Geisinger ${ }^{2,8^{*}}$

\begin{abstract}
Background: Spermatogenesis is a complex differentiation process that involves the successive and simultaneous execution of three different gene expression programs: mitotic proliferation of spermatogonia, meiosis, and spermiogenesis. Testicular cell heterogeneity has hindered its molecular analyses. Moreover, the characterization of short, poorly represented cell stages such as initial meiotic prophase ones (leptotene and zygotene) has remained elusive, despite their crucial importance for understanding the fundamentals of meiosis.

Results: We have developed a flow cytometry-based approach for obtaining highly pure stage-specific spermatogenic cell populations, including early meiotic prophase. Here we combined this methodology with next generation sequencing, which enabled the analysis of meiotic and postmeiotic gene expression signatures in mouse with unprecedented reliability. Interestingly, we found that a considerable number of genes involved in early as well as late meiotic processes are already on at early meiotic prophase, with a high proportion of them being expressed only for the short time lapse of lepto-zygotene stages. Besides, we observed a massive change in gene expression patterns during medium meiotic prophase (pachytene) when mostly genes related to spermiogenesis and sperm function are already turned on. This indicates that the transcriptional switch from meiosis to post-meiosis takes place very early, during meiotic prophase, thus disclosing a higher incidence of post-transcriptional regulation in spermatogenesis than previously reported. Moreover, we found that a good proportion of the differential gene expression in spermiogenesis corresponds to up-regulation of genes whose expression starts earlier, at pachytene stage; this includes transition protein-and protamine-coding genes, which have long been claimed to switch on during spermiogenesis. In addition, our results afford new insights concerning $X$ chromosome meiotic inactivation and reactivation.

(Continued on next page)
\end{abstract}

\footnotetext{
* Correspondence: sotelojos@gmail.com; adriana.geisinger@gmail.com

${ }^{\dagger}$ Equal contributors

'Department of Genomics, Instituto de Investigaciones Biológicas Clemente

Estable (IIBCE), Av. Italia 3318, 11,600 Montevideo, Uruguay

2Department of Molecular Biology, Instituto de Investigaciones Biológicas

Clemente Estable (IIBCE), Av. Italia 3318, 11,600 Montevideo, Uruguay

Full list of author information is available at the end of the article
} 
(Continued from previous page)

Conclusions: This work provides for the first time an overview of the time course for the massive onset and turning off of the meiotic and spermiogenic genetic programs. Importantly, our data represent a highly reliable information set about gene expression in pure testicular cell populations including early meiotic prophase, for further data mining towards the elucidation of the molecular bases of male reproduction in mammals.

Keywords: Spermatogenesis, Transcriptome, RNAseq, Flow cytometry

\section{Background}

Spermatogenesis is a very complex terminal cell differentiation process that yields mature sperm, and results from the expression of a specific genetic program $[1,2]$. It has been divided into three succesive phases: somatic proliferation of spermatogonia, meiosis, and spermiogenesis. Each of these phases is characterized by its own gene expression program, and all the phase-specific programs are executed in the testis in a simultaneous and coordinated way.

In the seminiferous tubules of adult mammals, cell types with different DNA content coexist: several types of G1 phase spermatogonia and secondary spermatocytes $(2 \mathrm{C})$, various stages of primary spermatocytes and G2 phase spermatogonia (4C), different steps of round and elongating spermatids (C), and spermatozoa (C). Besides, somatic Sertoli cells (2C) also reside inside the tubules, totaling over 30 diverse coexistent cell types. Moreover, seminiferous tubules are surrounded by peritubular myoid cells and immersed in a stroma containing fibroblasts, lymphocytes, mastocytes, macrophages, and Leydig cells, all of them $2 \mathrm{C}$.

The heterogeneity of testicular cell composition together with the lack of in vitro systems for spermatogenic cell culture [3] have been important drawbacks for gene expression studies along the different spermatogenic stages. Basically two approaches have been used in order to overcome these limitations. The first approach has been the analysis of RNA from whole testes of prepubertal animals at different ages representative of the first spermatogenic wave progression (e.g. [4-11]), where the transcripts that are present at one age but not at younger ages are attributed to the newly appeared cell types. However, this strategy does not allow undoubtedly assigning specific RNAs to a certain cell type within the heterogeneous population. Moreover, specific transcripts from very poorly represented cell types will probably escape detection, as they appear diluted in comparison to highly represented ones; even abundant transcripts from scanty cell types are usually hidden. Other than that, although it has been asserted that in rodents the first spermatogenic wave is synchronous $[6,7,11]$, we and others [12] have observed that this is not entirely true and therefore partial desynchronization will also contribute to wrong conclusions.
A second strategy has been the enrichment of stagespecific cell populations. Among separation techniques, the most widely used have been gravimetric decantation (Staput) [13-15] and centrifugal elutriation [16]. Due to the relative abundance and cell size difference, these methodologies only allow the successful separation of highly enriched fractions containing pachytene spermatocytes (PS; i.e., medium meiotic prophase), or round spermatids (RS; i.e., spermiogenesis), while other cell types are obtained at very low purity levels [16]. Even for PS and RSenriched cell populations, purity levels are at best around $80 \%$ ([16], and our own experience). As a consequence, highly sensitive modern analysis techniques (mostly PCRbased) can generate misleading results caused by the amplification of transcripts from contaminating cell types. A different methodological approach, flow cytometry (FCM), has been employed to analyze and sort different testicular cell populations with unprecedented purity levels based on DNA content together with differences in nuclear size, cellular size, complexity, and chromatin compaction $[12,17-20]$. Some other strategies such as laser-capture microdissection of specific spermatogenic stages [21] are very complex and require a highly experienced operator [22], and therefore have been only adopted in a limited number of laboratories (e.g. [23]).

The molecular characterization of meiotic prophase I early stages (leptotene and zygotene; LZ) is essential towards understanding the fundamentals of meiosis: mutations of meiotic genes that disrupt bouquet formation, chromosome alignment, meiotic synapsis, and recombination (crossing-over) are not able to reach the pachytene stage (P) often resulting in sterility [24-26]. However, the relatively short duration of these stages and consequently their low frequency in most rodent models has hampered their efficient purification $[19,20]$.

We have reported the sorting of LZ stages by FCM at very high purity levels (98\%), first in guinea pig (Cavia porcellus), a rodent that exhibits an unusually high representation of early meiotic cell populations [19], and more recently in mouse [27]. In the latter we used a DNA-specific, non-cytotoxic, vital dye (Vybrant DyeCycle Green [VDG]) that allowed an efficient discrimination of different meiotic stages (LZ from PS) as discrete populations in the dot plots. This dye is excited at $488 \mathrm{~nm}$, 
unlike bisbenzimidazole stains such as Hoechst that require a UV laser (reviewed in [28]). We have employed flow sorting using VDG in combination with an ultra-fast method for the preparation of testicular cell suspensions developed by our group, which renders excellent preparations while avoiding the use of enzymatic treatments [29, 30]. The speed of the cell suspension preparation together with the lack of enzyme treatments helps preserve delicate macromolecules such as mRNAs, while the avoidance of UV light exposure minimizes potential damage to nucleic acids.

During the past decade several large scale differential gene expression studies along spermatogenesis have been performed in rodents, most of them based on microarray technology and starting either from whole testes of prepubertal animals [4-10] or elutriation/Staput-enriched cell populations (mainly PS and RS) [23, 31-34]. Besides, a report by Fallahi et al. [35] has employed fluorescenceactivated cell sorting (FACS) to isolate meiotic cell stages for microarray expression analysis. Microarray studies have identified an important number of candidate genes for roles in the regulation of fertility and possible contraceptive targets (e.g. [4, 33]). Nonetheless, it has become evident that this technology is not the most suitable for testis-addressed gene expression studies as most microarrays are limited to known transcripts, and the sequences used for their construction do not contemplate testicular peculiarities such as the remarkable number of splice variants that are differentially expressed in spermatogenic cells (e.g. [36, 37]) .

Recently, next generation sequencing (NGS) has been applied to gene expression analysis along spermatogenesis. Besides its better sensitivity, NGS has the capability to identify and quantify novel transcribed regions and splice variants [11, 38, 39]. Two reports published hitherto have analyzed the fluctuations of gene expression patterns along spermatogenesis using whole testes at different time points during the first wave of murine spermatogenesis $[11,39]$. In one of these reports, a computational deconvolution approach has been coupled as an attempt to estimate cell type-specific gene expression [39]. A handful of studies have employed elutriation-enriched testicular cell populations from mouse $[38,40]$ and rat [41], although they mainly focused on a global analysis of testis transcriptome complexity and chromatin changes [38, 40], or dealt with non-coding RNAs [41]. In these studies PS were used as the representative meiotic stage and no information regarding LZ was provided (as stated above, elutriation does not allow to purify LZ). On the other hand, an RNAseq study aimed at the analysis of gene expression differences between the wild type and a knockout mouse included a cell fraction modestly enriched in LZ by Staput [42]. So far, no transcriptomic studies using FCM for high purity sorting of testicular cell populations together with RNAseq have been published.
Here, we report on a detailed analysis of gene expression patterns along mouse spermatogenesis by NGS. For the present study, we have taken advantage of the abovementioned protocols for ultra-fast preparation of testicular cell suspensions and high purity sorting with VDG, which rendered high quality, cell-type specific RNA for transcriptomic studies. The combined use of flow sorting and NGS, both extremely robust methodologies, allowed to obtain results concerning differential gene expression in the different spermatogenic stages with unprecedented reliability. Moreover, this is the first time that a highly purified LZ cell population is included in NGS studies. Remarkably, with this experimental approach we have been able to disclose gene core signatures regarding the meiotic and postmeiotic expression patterns, thus providing new insights into spermatogenesis gene regulation.

\section{Results}

\section{RNAseq of highly purified testicular cell populations}

In order to reliably assess gene expression changes between the different spermatogenic stages, we performed transcriptome analysis of FCM highly purified cell populations representative of landmark points along mouse spermatogenesis: $2 \mathrm{C}$, LZ, PS, and RS.

The optimal ages for obtaining the different cell fractions (maximum representation of each specific cell type, lowest proportion of possible contaminant cell types) were determined by monitoring the progress of the first spermatogenic wave by FCM analysis of the cell suspensions, and by microscopic observation of Epon-embedded cross sections of seminiferous tubules (Additional file 1: Figure S1A). Besides, meiotic prophase stages were scrutinized by confocal immunocytochemistry using an antibody against the main component of the lateral element of synaptonemal complexes, SYCP3 (Additional file 1: Figure S1B). Accordingly, we used 10-11 days postpartum (dpp) mice for purifying the highest amount of LZ spermatocytes without any PS contamination (Fig. 1a and b). Testes from different individuals of the same age were employed for the purification of the $2 \mathrm{C}$ fraction, which consists of a heterogeneous cell population containing spermatogonia and somatic cells (mostly Sertoli cells), and was used as a reference for the transcripts present in pre-meiotic and somatic testicular cell types. Besides, the choice of early prepubertal mice for the purification of the $2 \mathrm{C}$ fraction avoids the presence of spermatocytes II, which otherwise would co-purify with this fraction due to their DNA content.

PS were obtained from the testes of 24-25 dpp pups, which showed a relatively high representation of this cell type in the seminiferous tubules. Although the $4 \mathrm{C}$ fraction at that age also contains $\mathrm{L}$ and $\mathrm{Z}$ spermatocytes, the use of VDG stain allowed to clearly discriminate two subpeaks within this fraction, as follows (Fig. 1c): the leftmost $4 \mathrm{C}$ peak corresponded to spermatocytes in LZ stages and 

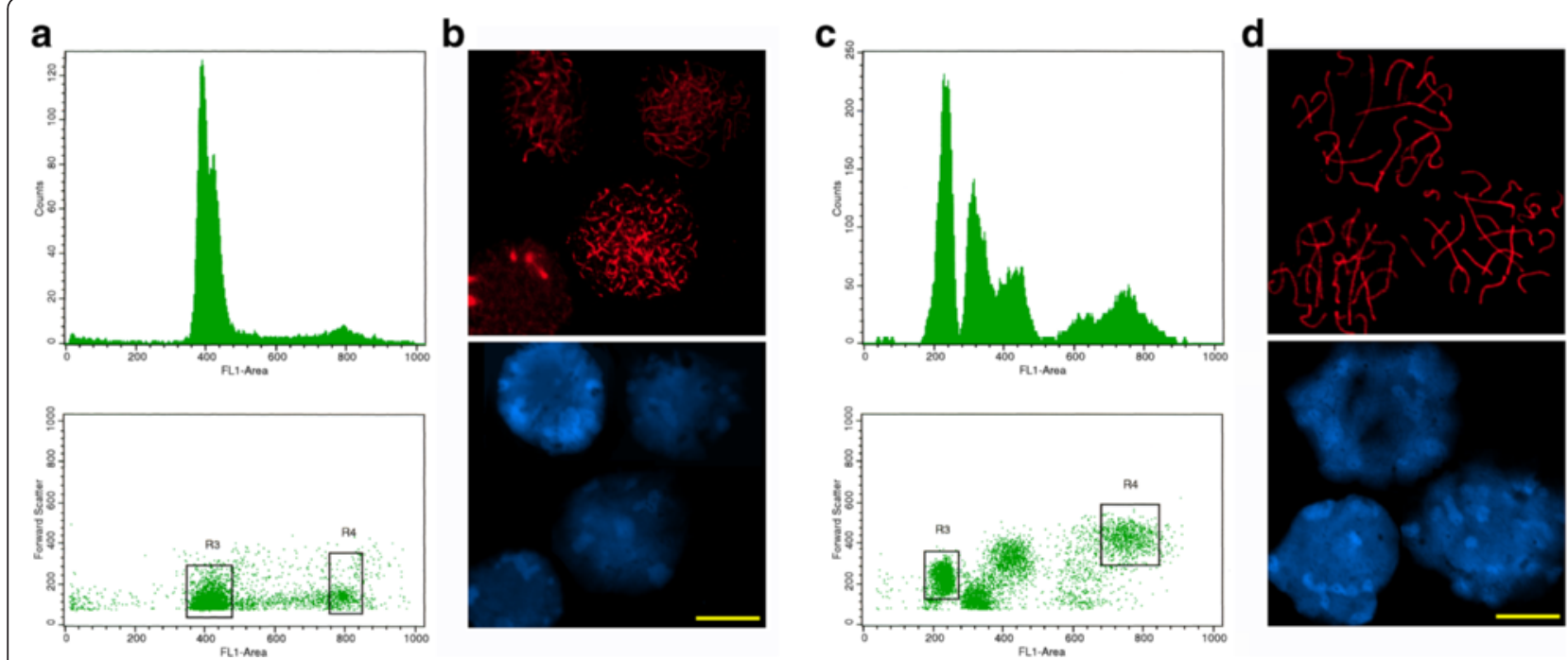

Fig. 1 Flow cytometric purification and immunocytochemical analysis of sorted testicular cell populations with VDG. Mice aging 10-11 dpp (a, b) and 24-25 dpp (c, d) were used. a, c. Dot plots depicting forward scatter (FSC-H) vs VDG fluorescence intensity and their corresponding histograms showing the gated cell populations. b, d. Confocal immunocytochemical analysis with anti-SYCP3 antibody (red) as a marker of the LZ (b) and PS (d) sorted fractions. Nuclei were counterstained with DAPI. Bars correspond to $10 \mu \mathrm{m}$

the rightmost one only contained PS, as shown by SYCP3 staining pattern (Fig. 1d; see also [27]). The visualization of PS as a separate, discrete population in the dot plots (see Fig. 1c) enabled its purification. Testes from individuals of the same age were employed for the purification of the $\mathrm{C}$ cell population. Despite the fact that a few elongating spermatids are also present at that age [17], the RS cell population was sorted without any detectable contamination from elongating spermatids. All four cell populations were obtained with $98 \%$ purity, as assessed by FCM reanalysis and immunocytochemical studies of the sorted fractions.

RNAs from the four purified cell populations were linearly amplified with the Ovation RNA-Seq System v2 in order to increase the yield without losing RNAs complexity [43], and subjected to Illumina sequencing. Total number of reads for each sample varied from 48 to 65 million, and the mapping rate of the reads was 56-80\% (Additional file 1: Table S1).

Using a high stringency (minimum read count of $\geq 10$ ), a total of 13,037 expressed protein-coding genes were identified only considering genes with $\geq 2$ reads per kilobase per million mapped reads (RPKM) in at least one of the four populations. We identified 9,436 expressed genes in the $2 \mathrm{C}$ population, 9,396 in LZ, 7,886 in PS, and 7,936 in RS. Among all the detected genes, 4,445 were shared by the four samples (Fig. 2).

\section{Major differences in gene expression patterns between LZ and PS cell populations}

We performed pairwise differential gene expression comparisons between cell populations in chronological order (2C vs LZ, LZ vs PS, PS vs RS) to detect the genes that changed their expression by at least 2-fold (Kal's test $p \leq 0.01$ ).

Hierarchical clustering of differentially expressed genes (DEG) showed relatively similar patterns between the 2C and LZ populations on one side, and between the PS and RS populations on the other. Moreover, the global pattern of turned on/turned off genes appeared practically reversed between the LZ and PS cell populations (Fig. 3a). Accordingly, the highest number of DEG was found when comparing LZ and PS cell populations, both

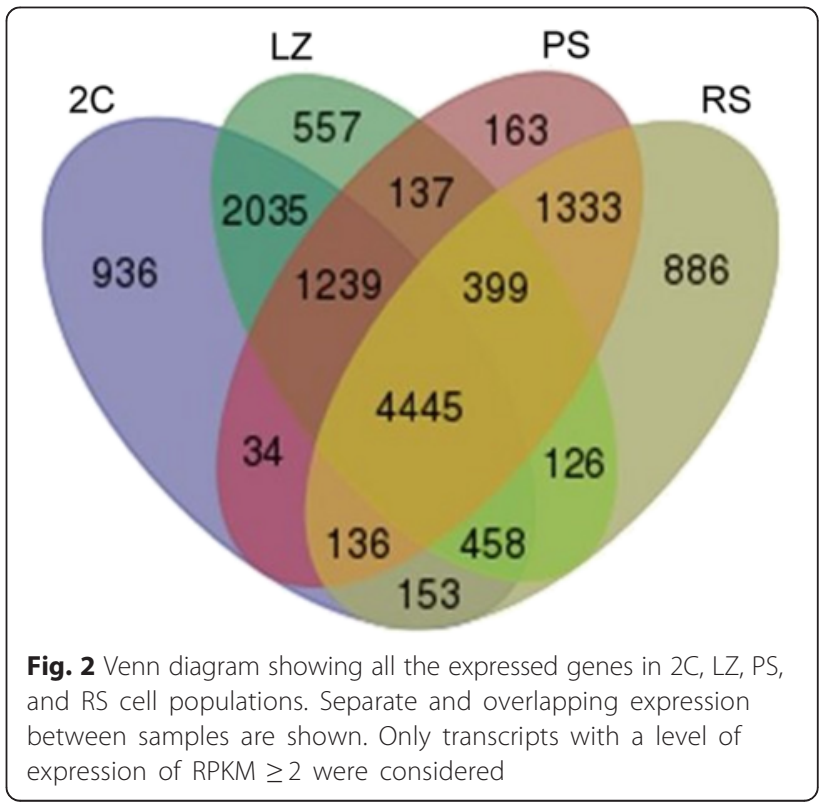




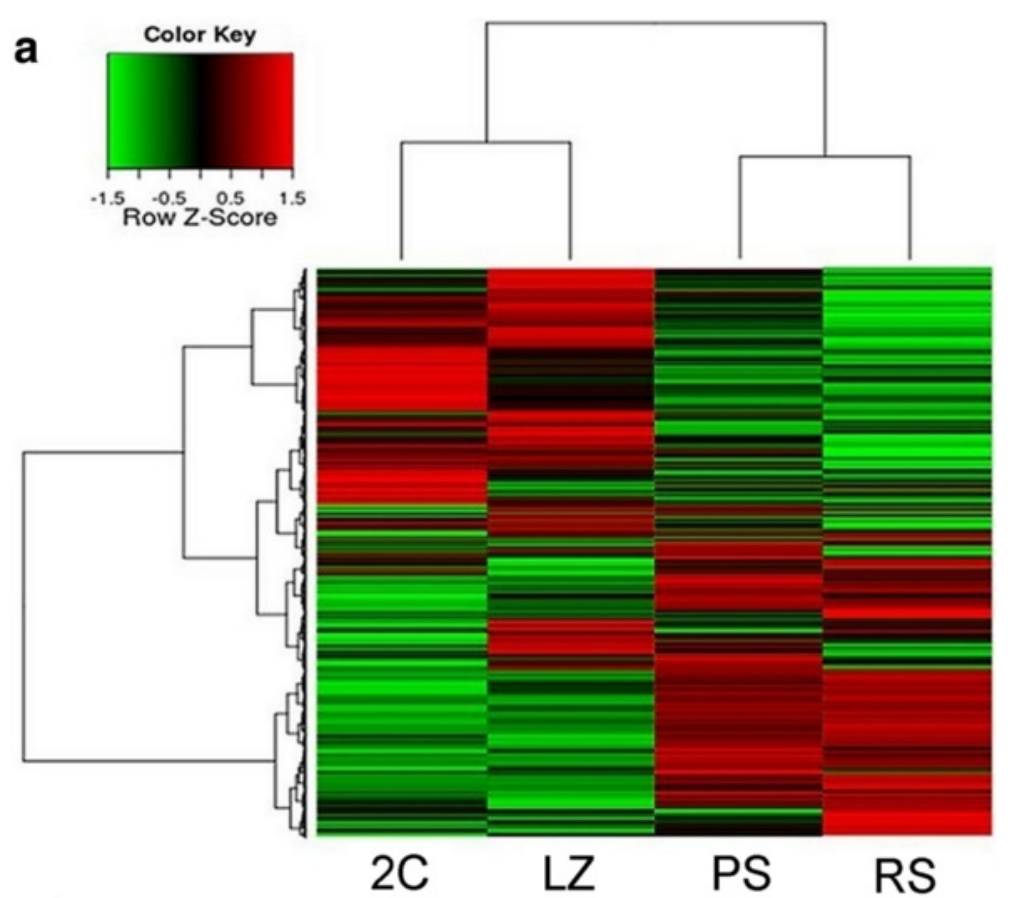

b

Downregulated
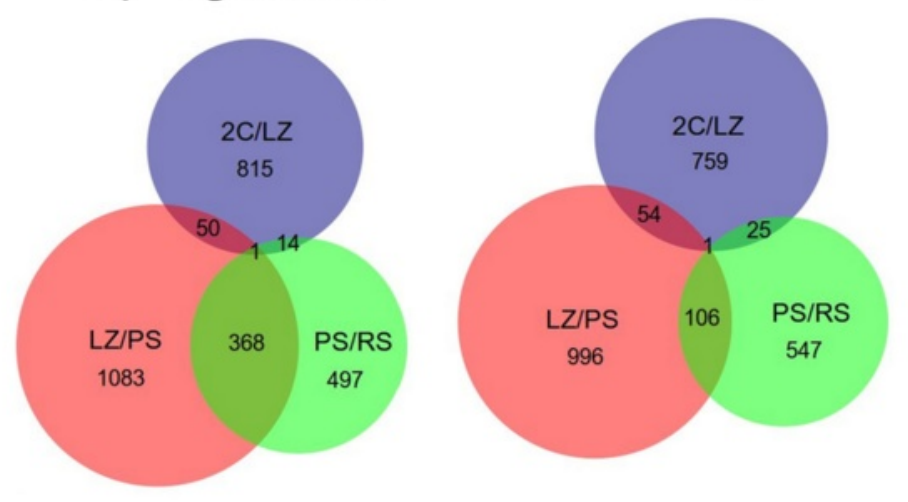

C
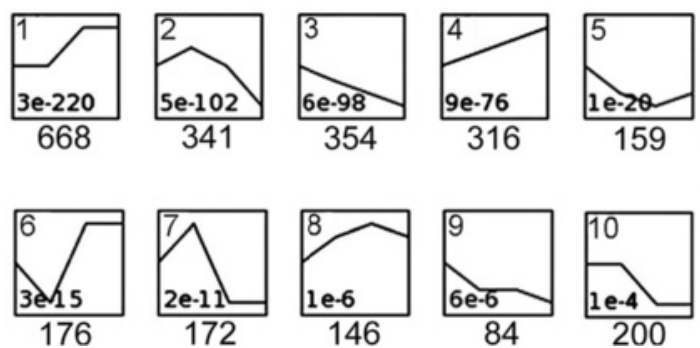

Fig. 3 Representation of DEG between pairwise sample comparisons of the four populations in chronological order. The following comparisons were performed: $2 C / L Z ; L Z / P S ; P S / R S ~(|F C| \geq 2$; Kal's test $p \leq 0.01)$. a. Heat map of expression levels and hierarchical clustering for the global gene expression in the four samples. All genes detected as differential in at least one sample were included. Z-score values are coded on the green-to-red scale (high expression: red; low expression: green). b. Venn diagram of up-regulated and down-regulated genes. Separate and overlapping expression between samples is shown. $\mathbf{c}$. Temporal expression profiles of DEG, ordered based on the $p$-value significance of the number of assigned vs expected genes. Only the 10 most significant profiles are shown. The $p$-value (bottom of each panel) and number of genes (below) for each profile are shown 
for up-regulated and for down-regulated genes (Table 1 and Fig. 3b). In addition, as illustrated in Fig. 3c, temporal expression profile analysis of the DEG showed that the highest number of genes under a single profile $(n=$ 668) pertains to genes that are up-regulated between LZ and PS (profile 1).

Next, we evaluated the number of up-regulated genes that were de novo turned on between comparisons. While 1451 of the 1502 up-regulated genes in the LZ/PS comparison were de novo turned on in PS, only 497 of the 880 up-regulated genes in RS were newly expressed, thus indicating that almost half of the up-regulated genes in RS correspond to increased expression (fold change $[\mathrm{FC}] \geq 2$ ) of genes already up-regulated in PS (see Fig. $3 \mathrm{~b}$ ). This shows that the $\mathrm{P}$ stage not only presents the highest number of up-regulated genes, but also the largest amount of de novo expressed genes of all the analyzed cell populations.

\section{A high number of meiosis-related genes are differentially expressed during early prophase}

The experimental protocol employed here rendered highly pure LZ cell populations. Thus, we were able to perform a detailed transcriptome analysis of the LZ stage, and compare it with previous and following stages. In mouse, $\mathrm{L}$ and $\mathrm{Z}$ together last in total 2-3 days. For this cell population, we found 880 up-regulated and 839 down-regulated genes (see Table 1). As expected, all seven genes coding for synaptonemal complex proteins (i.e. Sycp1, Sycp2, Sycp3, Syce1, Syce2, Syce3, and Tex12) and key genes involved in initial recombination events (e.g. Spo11, Dmc1, Rad51) [44] upregulate in LZ (see Additional file 2: Dataset S1).

To understand the underlying biological processes in the LZ cell population, we carried out gene ontology (GO) analysis of the DEG. For up-regulated genes, terms related to cellular metabolism, RNA and DNA metabolic processes, reproduction, chromatin organization, cell cycle, spermatogenesis, microtubule cytoskeleton organization, DNA repair, mitosis, meiosis, meiotic recombination, chromosome condensation and segregation, and synaptonemal complex, were among the most significant $(p<0.01)$ (Fig. 4a). On the other hand, down-regulated genes from $2 \mathrm{C}$ to $\mathrm{LZ}$ mostly fell into organ and tissue

Table 1 Total numbers of up-regulated and down-regulated genes in pairwise comparisons

\begin{tabular}{llll}
\hline Samples (comparison) & Total & UP & DOWN \\
\hline $2 \mathrm{C} / \mathrm{LZ}^{a}$ & 1,719 & 880 & 839 \\
LZ/PS $^{a}$ & 2,659 & 1,502 & 1,157 \\
PS/RS $^{a}$ & 1,559 & 880 & 679 \\
\hline
\end{tabular}

${ }^{a}$ Values correspond to the total, up, and down-regulated genes in group 2 relative to group 1 for each comparison (LZ relative to $2 C_{\text {; }} P S$ relative to $L Z$; $\mathrm{RS}$ relative to $\mathrm{PS}$ )

The different testicular cell populations were compared according to their temporal appearance along the spermatogenic wave $(|\mathrm{FC}| \geq 2 ; p \leq 0.01)$ development-related, and extracellular matrix and cell adhesion-associated categories $\left(p<10^{-7}\right)$. Besides, genes with shared expression between $2 \mathrm{C}$ and LZ (i.e. those that remained fairly constant in both lists, $-2<\mathrm{FC}<2$ ), were mostly related to translation, intracellular transport, mRNA processing, cellular macromolecule localization, generation of metabolites and energy, chromatin organization, cellular respiration, and other general metabolic processes $\left(p<10^{-5}\right)$. Thus, meiosis-related GO terms show significant enrichment during early meiotic prophase and not before.

Nearly half of the genes that were up-regulated in LZ (429) showed an expression peak, as they decreased before P (Fig. 4b and C). This expression peak is illustrated by temporal expression profiles 2 and 7 in Fig. 3c. GO analysis showed that this subgroup of genes (unique or differential of LZ stages) basically fell within the same categories as the whole group of up-regulated genes in the $2 \mathrm{C} / \mathrm{LZ}$ comparison $(p<0.01$; Additional file 1: Figure S2). This allows to define a set of genes whose function is related to meiotic processes, among others, that downregulate before the $\mathrm{P}$ stage. Interestingly, the gene list in the LZ peak included genes whose protein products are still observed or are known to be active beyond LZ stages (e.g. Top $2 a$ [45], Scml2 [46], and many others) and, in some cases, even during spermiogenesis (Additional file 2: Dataset S1). Examples of the latter are the genes coding for sperm surface-heat shock protein HSPA5 [47], TEX101 [48] (for the latter two see also Fig. 4c) and its interacting proteins DPEP3 [49] and LY6K [50], to name a few. For TEX101 and LY6K, their requirement for sperm migration into the oviduct and male fertility have been shown $[51,52]$.

In order to exemplify the high number of genes that show an expression peak during the short LZ stages, we selected two GO categories: "reciprocal meiotic recombination" (GO\# 0007131) and "meiotic chromosome segregation" (GO\# 0045132), which take place during the $\mathrm{P}$ stage and anaphase, respectively. All the genes within these two GO categories were clustered according to their expression values. As can be seen from the heat maps in Fig. 4d, genes in both categories were largely turned on in LZ; moreover, the expression of most genes dramatically decreased at the P stage.

\section{The pachytene transcriptome reveals widespread early expression of genes related to postmeiotic processes} $\mathrm{GO}$ analysis of the up-regulated genes in PS compared to LZ (LZ/PS) showed enrichment in completely different biological processes. Terms related to reproduction, spermatogenesis, gamete generation, spermatid differentiation and development, fertilization, cilium and flagellum assembly and motility, sperm-egg recognition, and binding of sperm to zona pellucida, were among the most significantly 


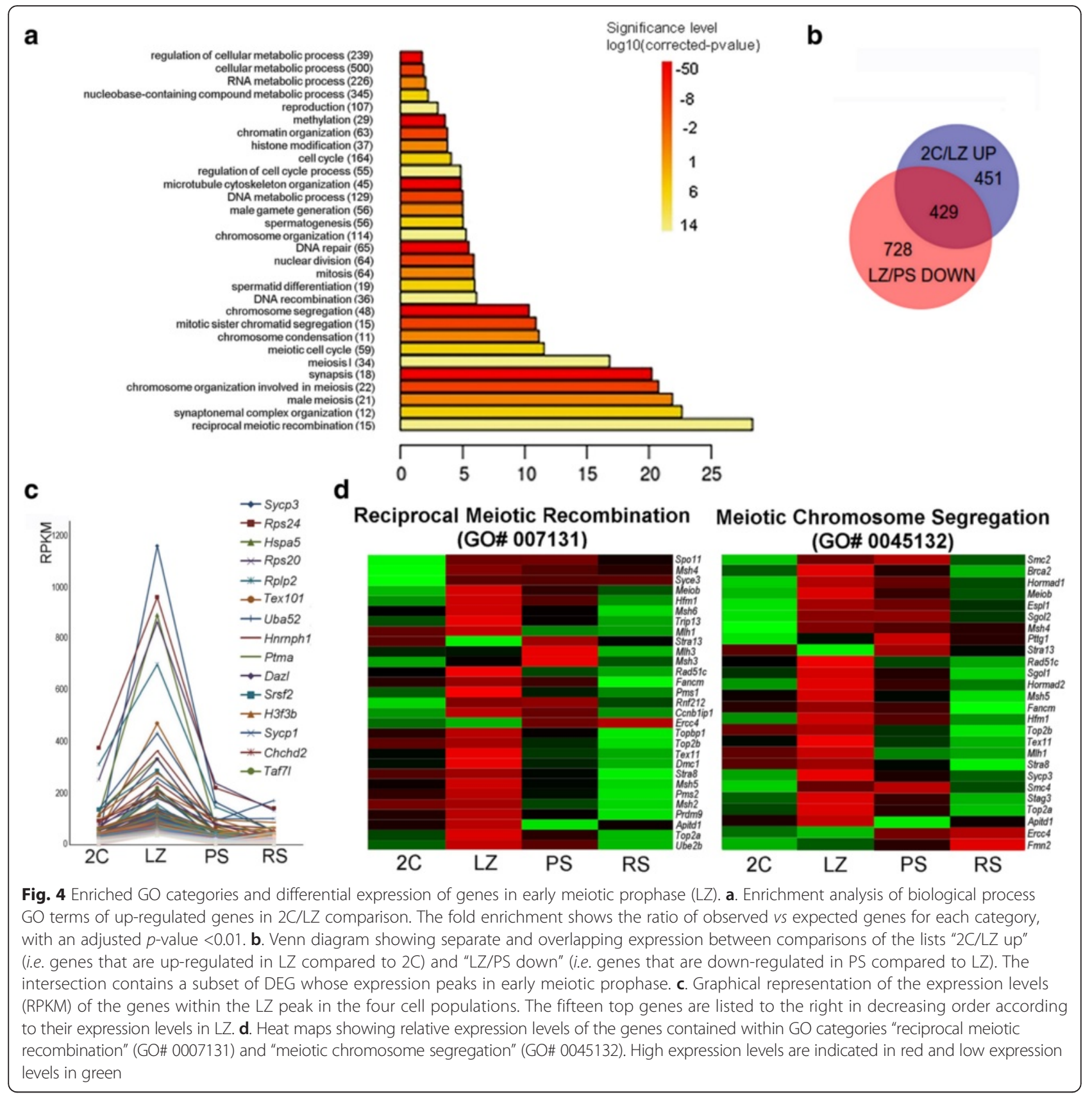

represented GO categories ( $p<0.01$; Fig. 5a). Basically, the same GO terms were enriched in PS/RS $(p<0.01$; Fig. 5b). In this regard, when pathway analysis was performed for each set of DEG, a considerable coincidence (three out of five) was found between PS and RS top canonical pathways, while no overlaps were found with LZ. Besides, four of the top five molecular and cellular functions were shared between PS and RS, while only two were in common with LZ (Additional file 3: Dataset S2).

It is worth mentioning that the number of genes within each of the above-referred GO categories was higher for LZ/PS than for PS/RS comparison (see Fig. $5 \mathrm{a}$ and $\mathrm{b}$ ), which indicates that more genes related to spermiogenesis-associated processes are upregulated in PS than in RS.

In order to exemplify the early expression of spermiogenesis-and fertilization-related genes, two processes that reflect late postmeiotic events were chosen for further analysis: sperm motility (GO\# 003017) and sperm-egg recognition (GO\# 0035036). As observed in Fig. $5 \mathrm{c}$, the vast majority of the genes included in both categories - whose role is related to the mature spermatozoa are activated at the $\mathrm{P}$ stage. 


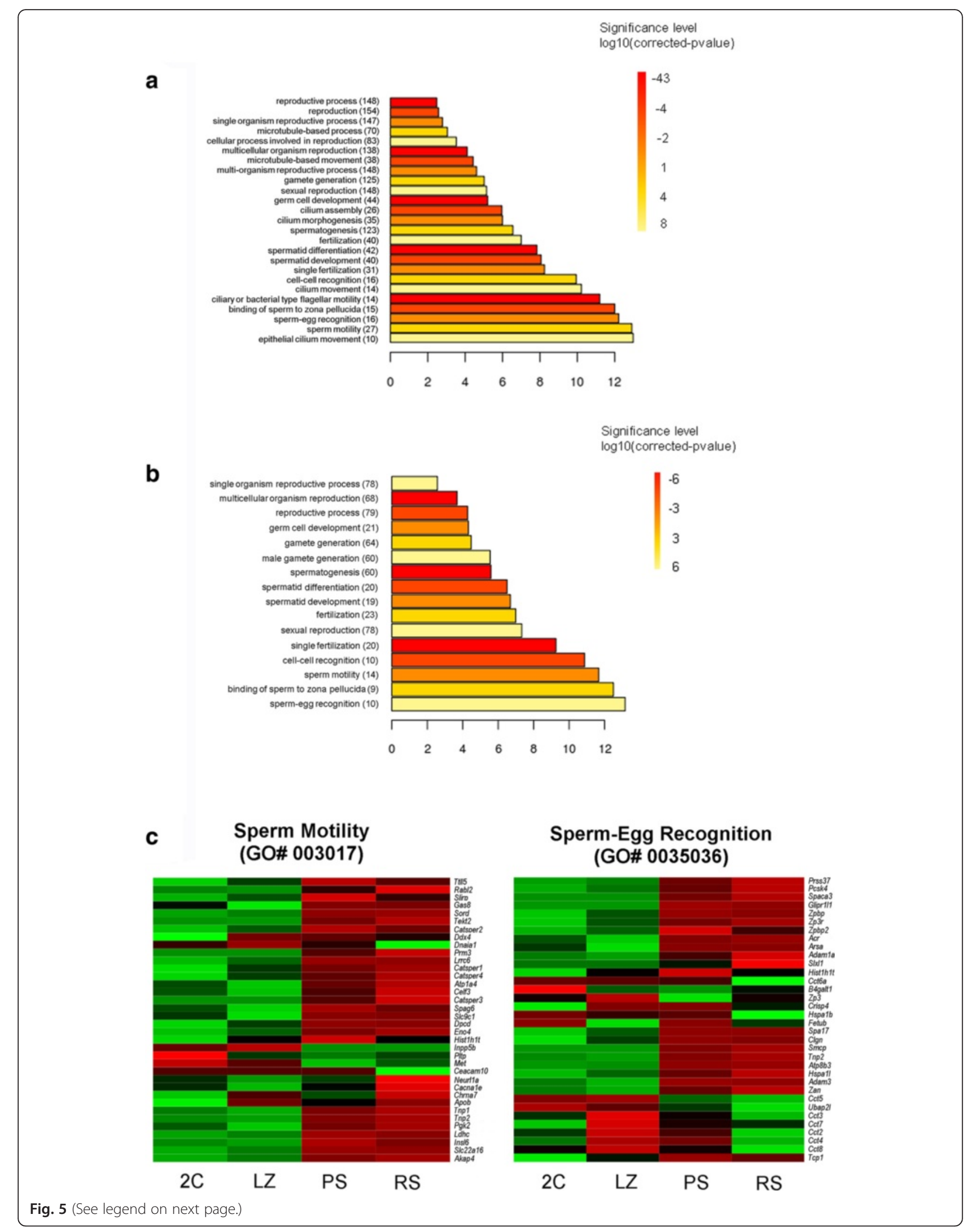


(See figure on previous page.)

Fig. 5 Enriched GO categories and differential expression of genes in PS and RS. a. Enriched biological process GO terms of up-regulated genes in the PS population compared to LZ. b. Enriched GO terms of up-regulated genes in RS compared to PS. $\mathbf{c}$. Heat maps of the GO categories "sperm motility" (GO\# 003017) and "sperm-egg recognition" (GO\# 0035036). High expression levels are indicated in red and low expression levels in green

\section{Validation by qRT-PCR}

To validate the RNAseq data, we selected 13 genes representative of the different expression profiles according to RNAseq results, and examined their expression levels via qRT-PCR in triplicates (three biological replicas for each cell population). In particular, we chose a gene representative of the $2 \mathrm{C}$ population (Col1a1), four genes that reflected the LZ expression peak (Sycp3, Dazl, Tex15, and Top2a), and eight genes that up-regulate in the PS cell population (Dnahc8, Tcte3, Atp8b3, Clgn, Spa17, Ldhc, Tnp1, and Prm1). With regard to the PS cell population, we deliberately selected genes that appeared as up-regulated in spermatocytes in our RNAseq study but whose protein products are known to be related to late post-meiotic functions: CLGN (calmegin) is a chaperone required for sperm-egg interaction [53]; LDHC (lactate dehydrogenase c) and DNAHC8 (dynein, axonemal, heavy chain 8) are related to sperm motility [54, 55]; ATP8B3 (ATPase, aminophospholipid transporter, class I, type $8 \mathrm{~B}$, Member 3 ) is involved in acrosome development and/or fertilization [56]; SPA17 (sperm autoantigenic protein 17) plays a role in sperm maturation, capacitation, acrosomal reaction, and interactions with the oocyte zona pellucida [57]; and TNP1 (transition protein 1) and PRM1 (protamine 1) are constituents of the chromatin of elongating spermatids and sperm, respectively $[58,59]$. Ppp $1 c c$ and Tax1bp1 were selected as control genes for normalization $[60,61]$ (see Additional file 2: Dataset S1).

The dynamic expression patterns of all genes in the four cell populations were consistent with both RNAseq analyses (CLC bio and edgeR) (Fig. 6a). Additionally, there was a high correlation between RNAseq and qRT-PCR data (Pearson $\mathrm{r}^{2}$ between 0.81-0.93 for CLC bio -Fig. 6b, and 0.73-0.93 for edgeR-derived results), thus supporting the reliability of our RNAseq data.

Besides, previous studies on the expression patterns for some of the selected genes were useful to further validate our results $[56,62,63]$.

\section{$\mathrm{X}$ chromosome gene expression signatures during meiosis}

Some peculiar aspects concerning the $\mathrm{X}$ chromosome in males have been reported. On one hand, a set of reports have indicated that in mouse the $\mathrm{X}$ chromosome is significantly enriched in spermatogonia-specific genes $[64,65]$ and impoverished in genes expressed during late spermatogenic stages [65]. In addition, it is acknowledged that in mammals the $\mathrm{X}$ chromosome is transcriptionally silenced during meiotic prophase I. This process, known as meiotic sex chromosome inactivation (MSCI), has been proposed to avoid recombination between non-homologous regions of the sex chromosome pair [66]. As the availability of highly purified spermatogenic cell populations enabled to follow these processes in detail, we used the above mentioned features to cross-check our data with previously published results.

Concerning gene distribution, we observed a significant enrichment on the $\mathrm{X}$ chromosome for proteincoding genes that are differentially expressed previous to MSCI (i.e. $2 \mathrm{C}$ and LZ peak; $p<5 \times 10^{-5}$ ). A moderate enrichment $(p<0.05)$ for RS-specific genes was evidenced as well (in agreement with [38]), while an important underrepresentation on the $\mathrm{X}$ chromosome was found for the whole set of genes that are up-regulated from $\mathrm{P}$ onwards (i.e. PS and RS together; $p<5 \times 10^{-4}$ ). This is in accordance with a previous work that identified an abundancy of early spermatogenic genes and a scarcity of late genes on the X chromosome of Spo11 ${ }^{-1-}$ mice, in which meiosis is blocked before the P stage [65].

Regarding MSCI, we analyzed the expression of all X chromosome-linked protein coding genes present in our RNAseq data (812 genes). We generated two heat maps representing the expression levels in the four populations: a first one ordered according to the position of the genes on the chromosome from $p$ to $q$ (Fig. 7a), and a second one showing their hierarchical clustering (Fig. 7b). This allowed to observe the inactivation of the $\mathrm{X}$ chromosome, which further validates our data. As previously reported in a microarray study [35], we detected a massive switch off of $\mathrm{X}$-linked genes between LZ and PS cell populations (see Fig. 7a). Interestingly, we identified a cluster of $\sim 70$ genes that showed an opposite behavior to that of most X-linked genes, as they escaped MSCI being up-regulated in PS (see Fig. 7b). Nearly half of these genes showed a 5-to 1000-fold increase from LZ to PS, and were clearly identified as differential of PS in our comparative analysis (Additional file 4: Dataset S3). Among those genes with a known function, many code for sperm-related proteins such as AKAP4 that is involved in sperm motility [67], CYPT1 that is a spermspecific component of the post-acrosomal perinuclear theca [68], CYLC1, which forms part of the sperm head cytoskeleton, and SPACA5, a sperm acrosome-associated protein, among others. Besides, five predicted proteins contain a H2A conserved domain, and are putative histone cluster 2 family members.

The heat map displayed according to gene position on the chromosome also evidences the partial transcriptional 


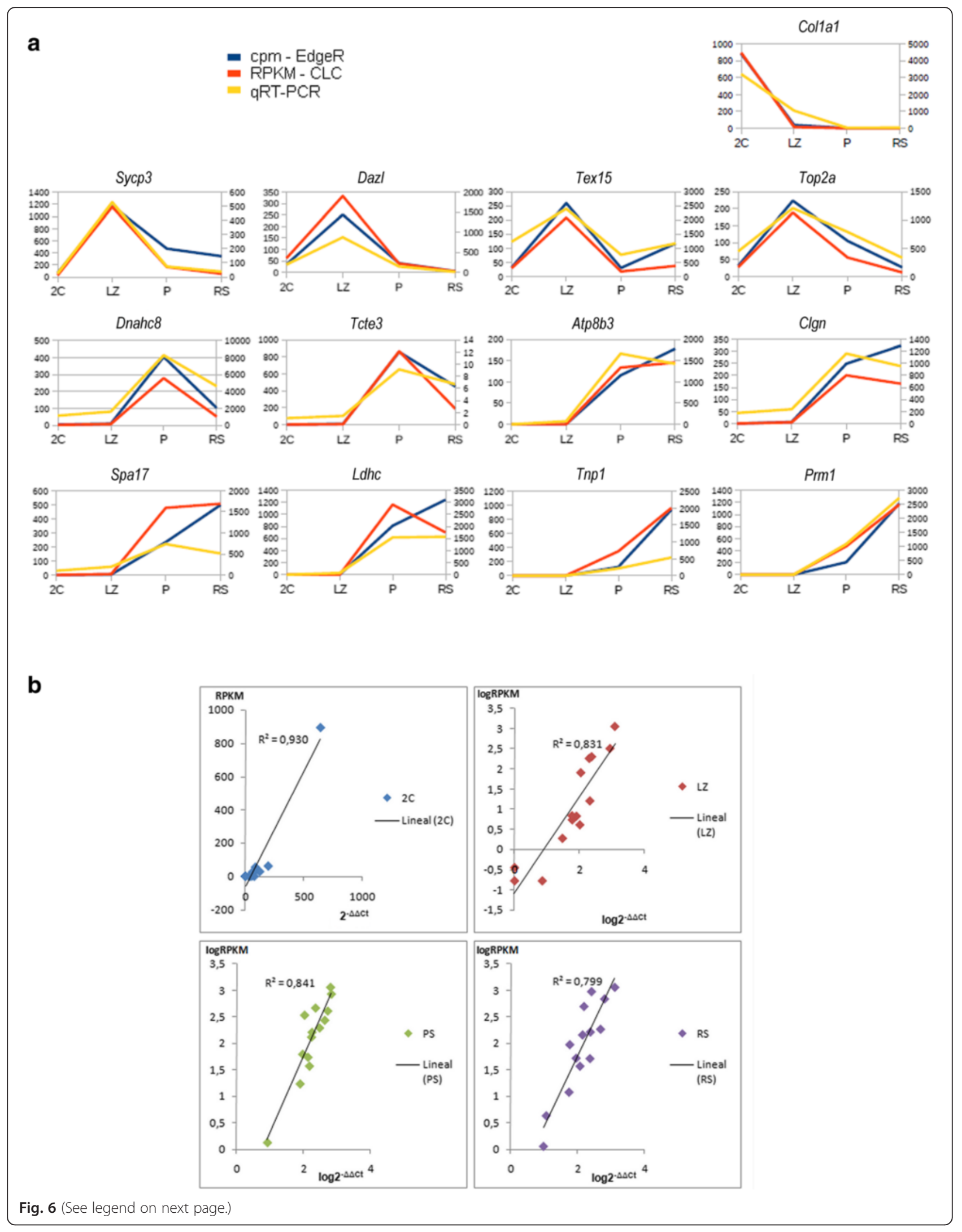


(See figure on previous page.)

Fig. 6 Dynamic expression patterns of 13 selected genes representative of the different expression profiles. The analyses were carried out by RNAseq (CLC bio and edgeR) and qPCR. a. Expression profiles obtained by RNAseq analysis (CLC bio: orange; edgeR: blue) and qPCR analysis (yellow). Col1a1: collagen, type 1, alpha 1; Sycp3: synaptonemal complex protein 3; Dazl: deleted in azoospermia-like; Tex 15: testis expressed 15; Top2a: DNA topoisomerase II, alpha isozyme; Dnahc8: dynein, axonemal, heavy chain 8; Tcte3: T-complex-associated-testis-expressed 3; Atp8b3: ATPase, aminophospholipid transporter, class I, type 8B, member 3; Clgn; calmegin; Spa17: sperm autoantigenic protein 17; Ldhc: lactate dehydrogenase C; Tnp 1: transition protein 1; Prm1: protamine 1. b. Correlation between the expression levels in RNAseq analysis (RPKM values of CLC bio analysis) and those obtained by QPCR analysis for the 13 selected genes in the four testicular cell populations

reactivation of X-linked genes in RS. Surprisingly, reactivated genes were not scattered along the $\mathrm{X}$ chromosome but mostly concentrated on the centromere-nearest chromosome half (see Fig. 7a).

\section{Discussion}

\section{Advantages of the experimental approach}

Few studies on differential gene expression along mouse spermatogenesis by means of NGS have been published up to now [11, 38-40]. All of them employed either whole testis or stage-specific enriched cell populations where the purity of the fractions was not optimal for a detailed analysis of gene expression patterns. Besides, most previous reports using enriched cell populations (including NGS [38, 41] and most microarray studies) have viewed PS as the representative meiotic prophase stage, and therefore it has not been possible to discriminate between transcripts synthesized for the first time in PS and those originated during earlier meiotic prophase stages.

Dealing with the technical limitations described above, we have incorporated some key methodological improvements thus significantly contributing to the reliability of the results: i) the fast method for the preparation of the testicular cell suspensions [29, 30], and the use of VDG [27] that is a vital dye excitable at $488 \mathrm{~nm}$, both help preserve the integrity of the RNAs; ii) the flow sorting protocol used here enabled to obtain all the testicular cell populations at very high purity rates, allowing gene expression studies with negligible cross contamination. As a consequence, we can assert that the results from the RNAseq studies reflect differential expression in each of the cell types to an unprecedented accuracy level (see also below); iii) the availability of a highly purified LZ fraction (identified as a discrete cell population by FCM) for RNAseq analysis allowed to assess the temporal expression profile along key meiotic prophase I stages, in contrast to the use of whole testes from animals of increasing ages that permits to ascertain when genes are switched on, but not their switch off time point. Here, the gene expression pattern of LZ spermatocytes was compared with that of PS, thus enabling to follow the up-and downregulation of the different genes.

All the above mentioned improvements allowed us - to our knowledge for the first time - to reliably relate stagespecific gene expression signatures (GES) with the processes that take place at the different spermatogenic stages.

\section{Main contributions to the knowledge of gene expression patterns along spermatogenesis}

An important conclusion from the analysis of GES in this work is that a good deal of genes involved in early as well as late meiotic processes are already on at early meiotic prophase (i.e. LZ). As the GO enrichment analysis of the transcripts whose expression levels remain fairly constant between $2 \mathrm{C}$ and $\mathrm{LZ}$ cell populations mostly rendered terms associated with general processes and very
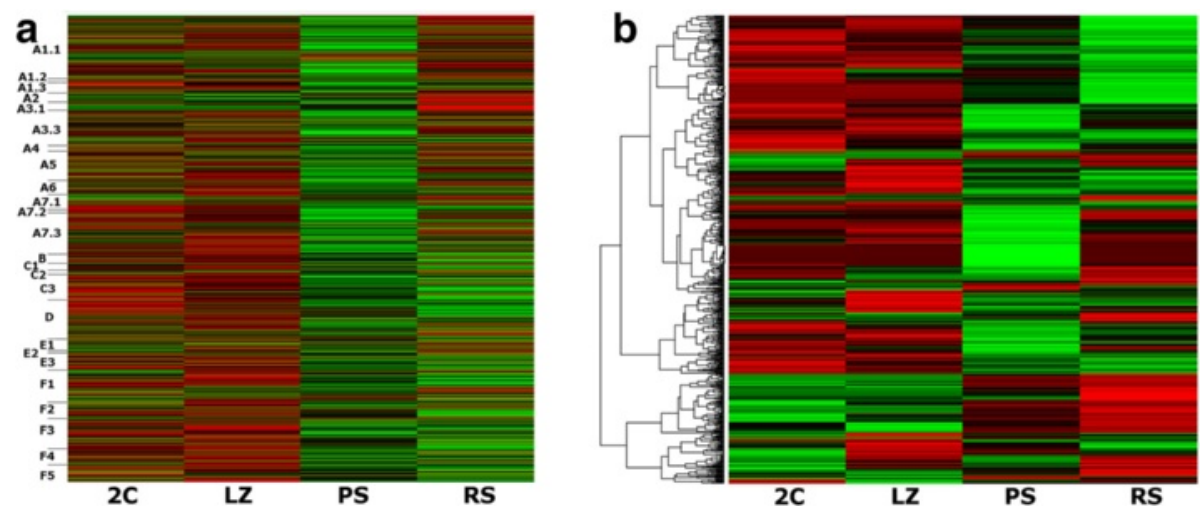

Fig. 7 Heat maps showing relative expression levels of X-linked protein-coding genes in the four cell populations. a. The genes were ordered according to their position on the chromosome from $p$ to $q$. Chromosome bands are indicated to the left of the figure. $\mathbf{b}$. Hierarchical clustering. High expression levels are indicated in red and low expression levels in green for both heat maps 
few meiosis-related ones, we can conclude that most meiosis-related genes that are expressed in LZ, are upregulated at the beginning of meiosis. Remarkably, a high number of these genes are only on for the short time lapse of LZ (2-3 days), being down-regulated before P. Therefore, the temporal expression pattern of many meioticallyexpressed genes is evidenced as a sharp LZ peak. More intriguingly, a small group of genes whose products are known to be present during late spermiogenic stages were also contained within the LZ peak set.

The two GO categories we chose for exemplifying the early transcription of meiotic genes, which represent meiotic prophase ("reciprocal meiotic recombination") and late meiotic events ("meiotic chromosome segregation") respectively, are illustrated in Fig. 8. Noteworthy, there is a gap between the time when these programs are transcriptionally activated, and the time when they are executed. Moreover, as stated above, many of the implicated genes are down-regulated before P. A logical conclusion of the aforementioned is that these transcripts must be mostly translated in LZ (i.e. before their degradation) and, for those proteins whose product remains present/active beyond $\mathrm{LZ}$, the protein should be kept for longer. In this regard, a recent proteomic study described different regulation mechanisms for the dynamic gene expression changes that take place during spermatogenesis [69]. Interestingly, one of those mechanisms, which the authors termed "transcript degradation", refers to genes whose mRNA levels drop from spermatogonia to PS while their protein levels remain relatively constant until marked for degradation at a later stage. Despite the facts that only a limited number of proteins were identified in that study, and that it did not include the LZ stages, "transcript degradation" would probably describe the regulatory mechanism for many genes within the LZ peak.

Another striking result is the massive change in GES at the P stage, which we named as "the pachytene switch". The general profile of up-regulated and down-regulated genes was more similar between $2 \mathrm{C}$ and $\mathrm{LZ}$ cell populations on one side, and amid PS and RS on the other. These findings are in agreement with a couple of microarray studies reporting a global expression switch in the testicular transcriptome during the progression from $\mathrm{Z}$ to $\mathrm{P}[10,35]$. However, we have demonstrated here for the first time that the genes which turn on during the $\mathrm{P}$ switch are mostly related to postmeiotic processes (see below) and not to meiosis, as previously thought (e.g. [10]).

Surprisingly, the number of DEG in RS was lower than that of PS, thus contradicting some previous microarray studies [7, 34]. Moreover, almost half of the up-regulated genes in $\mathrm{RS}(\mathrm{FC} \geq 2)$ were previously identified as up-regulated in LZ/PS. This supports the idea that the biggest change in gene expression patterns takes place at the $\mathrm{P}$ stage (i.e. during meiotic prophase I) and not at the beginning of spermiogenesis as previously stated. Besides the fact that microarray analyses of spermatogenic transcriptome were partial, the different results could be partly due to the low sensitivity of the microarray technique in comparison to RNAseq [70].

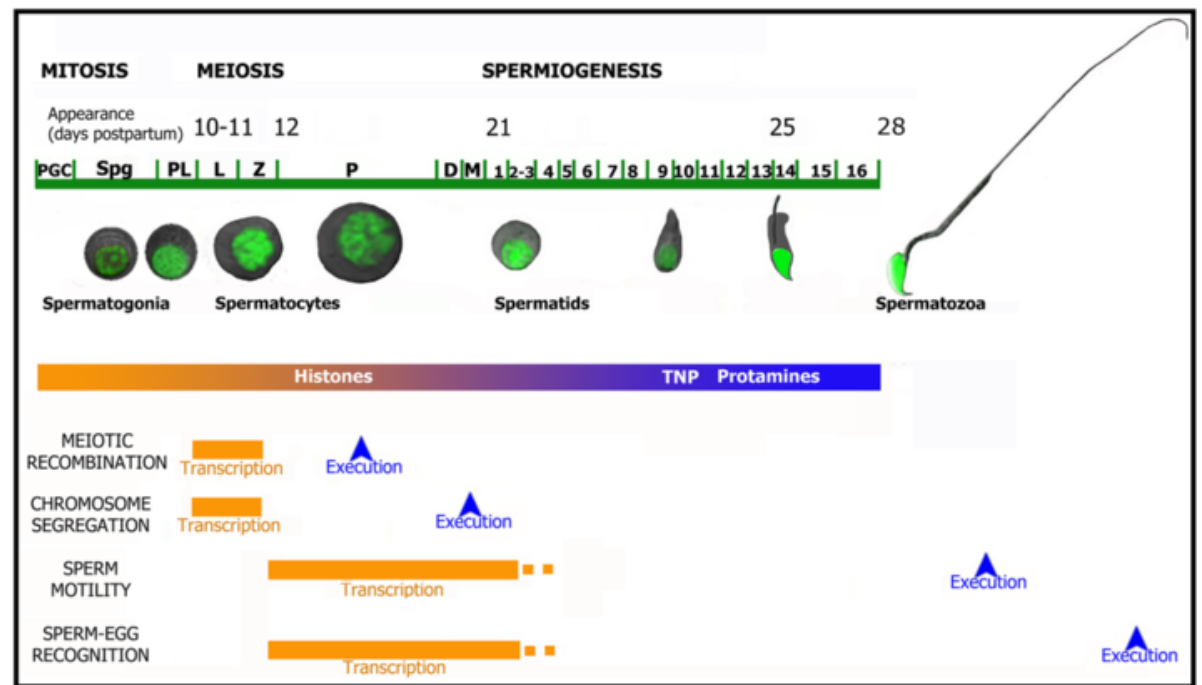

Fig. 8 Representation of the transcription and execution times of four selected GO categories. The diagram represents the time when the biological processes shown in the heat maps in Figs. $4 \mathrm{c}$ and $5 \mathrm{c}$ are transcriptionally activated, and when these processes are executed along the first spermatogenic wave in mouse. The onset (in dpp) for the different stages along the first spermatogenic wave is denoted on top. The time of histone substitution - first by TNP and then by PRM - is also represented. PGC: primordial germ cells; Spg: spermatogonia; PL: preleptotene; L: leptotene; Z: zygotene; P: pachytene; D: diplotene; M: meiotic divisions 
We found that the $\mathrm{P}$ switch is accompanied by an overall change in the involved biological processes, indicating that - in terms of differential gene expression LZ and PS are committed to the transcription of different spermatogenic programs, despite both being primary spermatocytes. Interestingly, while LZ spermatocytes differentially express a high number of meiotic genes, PS mostly turn on spermiogenesis-related genes, thus revealing an apparent inconsistency between the meiotic role of the PS - which reflects its protein content, largely related to meiotic recombination - and its differential mRNA profile. In accordance with this, when we selected two GO categories indicative of processes that take place in mature sperm ("sperm motility" and "spermegg recognition") for further analysis, the gap between the transcriptional activation time of the genes within both categories (mostly the P stage) and the execution time of these processes was evident, as illustrated in Fig. 8. Moreover, qRT-PCR results allowed to confirm the early turn on during the P stage of some selected genes whose products are known to be required for sperm functionality.

The existence of translational delays in spermatogenesis is well known [58, 71], and has been associated to the design of a strategy to regulate protein synthesis in cells that do not transcribe, as transcription in elongating and elongated spermatids is silenced after sequential histone replacement first by transition proteins (TNP) and then by protamines (PRM) [58, 59]. Translational repression has been adopted as a strategy to regulate the time of synthesis for proteins whose production in earlier spermatogenic stages (e.g. RS) would be detrimental (e.g. [58, 72]). Besides, post-transcriptional regulation mechanisms are acutely sensitive and can respond fast to environmental changes, as required in reproductive systems [73]. The mechanisms employed to achieve these unusually high levels of post-transcriptional regulation may involve mRNA sequestration as free ribonucleoprotein particles (RNPs) [8], binding of repressor proteins to UTRs of testisspecific transcripts (e.g. [74]), regulation of poly (A) tails length [71], use of upstream repressor open reading frames (uORFs) [75], participation of microRNAs, piRNAs [76], and antisense long non-coding RNAs (lncRNAs) [69, 77], and retention of RNAs in the chromatoid body [78], among others.

Although all the above-mentioned regulatory mechanisms have been extensively studied in spermatogenic cells, it is generally accepted that most transcripts whose protein products are required in elongating/elongated spermatids are transcribed by RS $[8,34]$. In spite of that, there are some reports of genes whose transcripts start to appear in spermatocytes and are translationally inactive until their protein is first detected in spermatids, such as $\operatorname{Pgk} 2[79,80]$ and others. Our findings show that the transcription of genes for spermatid- and sperm-specific proteins in PS is a much more widespread phenomenon than previously thought.

These results would be in agreement with the proteomic study by Gan et al. [69], who compared their data with publicly available transcriptomic information from microarray studies. They reported that of 253 proteins with high expression in RS and elongated spermatids, $54 \%$ were translationally repressed in PS, $60 \%$ of which were derepressed later on in RS. Although important spermiogenesis-related proteins are missing in Gan's list (e.g. PRM, TNP), we contrasted our transcriptomic results with the expression data of their spermatid-specific cluster. Interestingly, according to our RNAseq data, $67 \%$ of the proteins from that cluster appeared as translationally repressed in PS, $70 \%$ of which were derepressed in RS (Additional file 5: Dataset S4). LDHC [54], AKAP4 [67], and CLGN [53], are examples of proteins within this category. In view of these results, it is tempting to speculate that the great length of the $\mathrm{P}$ stage in all the studied metazoan species could be related, at least in part, to the partial turning off of the meiotic gene expression program, and the turning on of the spermiogenic one.

A particularly surprising outcome concerned the PRM and TNP. It has been long stated that their mRNAs in mouse, rat and human start to be transcribed in RS [81-85] and remain repressed until the stages of elongating spermatids, when they are translated [86, 87]. This means that in mouse, for example, this repression mechanism would be operative for up to a week. The mechanisms for post-transcriptional regulation of these mRNAs have been extensively studied [88], and it is known that abnormal Prm and Tnp expression including premature translation causes spermiogenesis arrest and infertility (e.g. $[72,89,90])$. Interestingly, in this work we found that although RS showed the highest Prm and Tnp mRNA levels among the four analyzed cell populations, Prm and Tnp genes were turned on and exhibited significantly high mRNA levels as early as during the $\mathrm{P}$ stage, especially Prm1, Tnp1 and Tnp2 (see Additional file 2: Dataset S1). This was confirmed by qRT-PCR for Prm1 and Tnp1. Moreover, Prm1, Tnp1 and Tnp2 were among the 20 top highly expressed transcripts in PS. Thus, our findings place the switching on of Prm and Tnp in mouse between one and two weeks earlier than previously thought, and indicate that the repression mechanisms that regulate their translation time must be active for much longer than anticipated. Remarkably, an early work by Iatrou et al. [91] had already reported the presence of Prm mRNA in primary spermatocytes in the rainbow trout by quantifying Prm cDNA-RNA hybrid formation.

Another interesting result was obtained in relation to Dazl (deleted in azoospermia-like), which encodes a germ cell-specific RNA-binding protein that is required for the differentiation of germ cells in vertebrates [92]. 
Controversies exist concerning the expression pattern of Dazl. While it has been reported that in adult mice Dazl expression is restricted to premeiotic stages [93], other studies have suggested its expression all through germ cell development, with high levels in PS [94]. Our NGS results, confirmed by qRT-PCR, show that Dazl exhibits a sharp LZ transcription peak. This fact remained unnoticed until now, probably due to the lack of expression studies using isolated LZ cell populations. This result is consistent with the finding that DAZL binds Sycp3 and Mvh (mouse vasa homolog, also known as Ddx4) mRNAs in vivo $[95,96]$, both of which are up-regulated in LZ as well (see Additional file 2: Dataset S1).

Finally, we decided to use our RNAseq data in order to analyze some particular spermatogenesis-related aspects on the X chromosome and compare our results with previously reported ones. In this regard, we have been able to follow MSCI on heat maps. A massive inactivation was observed between LZ and PS in agreement with previous results [35]. Moreover, we detected an important enrichment on the $\mathrm{X}$ chromosome for genes expressed during early spermatogenic stages, which is also coincidental with published reports (e.g. $[64,65])$. Interestingly, our results also disclose some novel insights regarding $\mathrm{X}$ chromosome behavior during spermatogenesis. First, the availability of highly pure LZ cell populations for direct comparison with PS allowed us to identify a cluster of genes that - contrary to the general trend - are up-regulated in PS. In this connection, although protein-coding genes that escape MSCI have been found in the domestic dog and some evidence suggests that MSCI might not be totally complete in humans as well [97], so far no X-linked mRNA genes had been reported to escape MSCI in mouse [98]. Many of the murine X-linked genes that appear as up-regulated in PS in our list, code for proteins that are functional in elongated spermatids and sperm. This would be in agreement with the massive switch on of spermiogenesis-related genes in PS reported above, and suggests that the expression of these genes must be subject to a specific epigenetic regulation that allows avoiding MSCI due to their importance for the development of healthy sperm. Besides, a number of X-linked genes coding for predicted histone H2Afamily members also appeared as up-regulated in PS. Several testis-specific H2A variants are known to be involved in chromatin dynamics in spermatids by assisting in the displacement of histones by TNP $[99,100]$. Moreover, some of them remain stably associated with the genome in mature sperm [101]. We speculate that these Xlinked H2A genes that are activated in PS, escape MSCI because they would be somehow required for chromatin reorganization in spermatogenic cells.

Another surprising finding was the differential activation of gene expression along the $\mathrm{X}$ chromosome in $\mathrm{RS}$, with a notably higher number of up-regulated genes on the centromere-nearest chromosome half. This suggests undisclosed mechanisms of epigenetic regulation for transcriptional reactivation in RS. Interestingly, a similar reactivation pattern has been observed for the dog [97].

\section{Conclusions}

This work represents an important advance regarding testicular transcriptome analyses in mouse. First, RNAseq technology was combined for the first time with a powerful flow cytometry-based protocol to sort highly pure spermatogenic cell populations, which allowed to obtain information about stage-specific gene expression with unprecedented reliability. Second, transcriptome profiling by RNAseq for early prophase meiocytes is reported here for the first time. Using the abovementioned improvements we disclosed here the following novel results: a) an important proportion of the meiotic program is already on at early meiotic prophase; b) a considerable number of genes have a marked expression peak at LZ stages, their transcripts being present for a very short time lapse; c) there is a massive change in GES at the P stage; d) the largest number of genes related to spermiogenesis and sperm functionality are turned on in PS, thus revealing a higher incidence of posttranscriptional regulation in spermatogenesis than previously stated; e) an important part of differential gene expression in RS corresponds to the up-regulation of genes which turn on earlier, during the $P$ stage; $f$ ) a cluster of X-linked genes in mouse are up-regulated in PS, thus escaping MSCI.

Taken together, our data provide a highly reliable information set about gene expression in purified spermatogenic stage-specific cell populations including early meiotic prophase, for further studies on the molecular bases of male reproduction in mammals.

\section{Methods \\ Animals}

Male CD-1 Swiss mice (Mus musculus) at different ages (10-11 and 24-25 dpp) were obtained from the animal facility at Instituto de Investigaciones Biológicas Clemente Estable (IIBCE, Montevideo, Uruguay). Flow sorting was performed on testicular cell suspensions of pooled material from a dozen pups aging 10-11 dpp and three to four mice aging 24-25 dpp per assay. Animals were euthanized by cervical dislocation (see Ethics Approval below).

\section{Preparation of cellular suspensions}

Testicular cell suspensions were prepared by a procedure previously described in our laboratory [27, 29]. Reagents and plasticware were handled in RNAse-free conditions. Briefly, testes were dissected into $35 \mathrm{~mm}$ glass Petri dishes containing ice-cold separation medium $(10 \% \mathrm{v} / \mathrm{v}$ fetal calf serum in Dulbecco's Modified Eagle's medium [DMEM], 
with high glucose and L-glutamine), and cut into 8$10 \mathrm{~mm}^{3}$ pieces after removal of the tunica albuginea. Between three and four of these pieces per round were immediately placed into a sterile disposable disaggregator unit (Medicon; Beckton-Dickinson [BD], CA) plus $1 \mathrm{~mL}$ of ice-cold separation medium, and processed for $30 \mathrm{sec}$ in the Medimachine System (BD), an automated electromechanical solid-tissue disaggregator. The resulting cell suspension was recovered from the Medicon unit with a $5 \mathrm{~mL}$ disposable syringe, sequentially passed through two $50 \mu \mathrm{m}$ Filcon filter units (BD), and placed on ice. Cells were counted by means of a Neubauer chamber and resuspended at a concentration of up to $3-5 \times 10^{6}$ cells/mL in separation medium. NDA (2-naphthol-6,8disulfonic acid, dipotassium salt; Chemos $\mathrm{GmbH}$, Regenstauf, Germany) was added to the suspension to a final concentration of $0.2 \%(\mathrm{w} / \mathrm{v})$ in order to prevent cell clumping.

\section{Cell analysis and sorting by flow cytometry}

Mouse testicular cell suspensions were analyzed and sorted following the method earlier described by Rodríguez-Casuriaga et al. [27]. In brief, cell suspensions were stained for $1 \mathrm{~h}$ at $37^{\circ}$ with VDG (InvitrogenLife Technologies, Carlsbad, CA) at a final concentration of $10 \mu \mathrm{M}$. Samples were analyzed and sorted with a FACSVantage flow cytometer (BD) furnished with an argon ion laser (Coherent, Innova 304) tuned at $488 \mathrm{~nm}$ of excitation wavelength $(100 \mathrm{~mW})$. A $70 \mu \mathrm{m}$ nozzle was selected to perform FCM analysis and cell sorting. Fluorescence emitted from VDG was collected in the FL1 channel using a 530/30 band pass filter. To optimize fluorescence detection, instrument linearity, and doublet discrimination performance, DNAQC particles (BD) were used. CELLQuest software (BD) was applied to analyze the following parameters: forward scatter (FSC-H), side scatter (SSC$\mathrm{H}$ ), pulse-area or total emitted fluorescence (FL1-A; VDG fluorescence intensity), and pulse-width or duration of fluorescence emission (FL1-W). Doublets were excluded using dot plots of FL1-A vs FL1-W. Sorting regions for 2C, LZ, PS and RS were determined on VDG fluorescence intensity $v s$ FSC-H dot plots.

The $2 \mathrm{C}$ and LZ cell populations were classified from testicular cell suspensions of individuals aging 10-11 dpp, while the PS and RS cells were obtained from 24-25 dpp ones (different animal pools were used to obtain each cell population in order to avoid paired samples for NGS analysis). Cells were sorted at a rate of $500-1,000 / \mathrm{sec}$. Sorting mode was set in Normal-C, and 3 sorted drops as envelope were used. During the sorting procedure, sample and collecting tubes were maintained at $4^{\circ}$ with a dedicated refrigeration unit (Lauda, Brinkmann, Delran, NJ) connected to the flow cytometer. Cells were collected into $12 \times$ $75 \mathrm{~mm}$ sterile polystyrene tubes containing $0.5 \mathrm{~mL}$ PBS treated with $0.1 \%$ DMPC (PBS-DMPC) and subsequently spun down (500 g, $10 \mathrm{~min}, 4^{\circ}$ ), washed with PBS-DMPC, deep frozen in liquid nitrogen, and stored at $-80^{\circ}$.

\section{Microscopical observations and immunocytochemistry}

In order to determine the optimal age for LZ enrichment in the absence of PS contamination, whole testes of pups ranging from 9 to $14 \mathrm{dpp}$ (sampled at one-day age differences) were fixed in $0.1 \mathrm{M}$ phosphate buffer ( $\mathrm{pH}$ 6.8) containing $2.5 \%$ glutaraldehyde, post-fixed in $1 \%$ osmium tetroxide, and embedded in Epon (Durcupan ACM Fluka, Sigma-Aldrich, St. Louis, MO) as previously reported [19]. $1 \mu \mathrm{m}$ sections were cut with a Power Tome XL Ultramicrotome (Boeckeler Instruments, Tucson, AZ), stained with toluidine blue, and examined by light microscopy with an Olympus FV300 confocal microscope. Photographs were taken with an Olympus DP70 digital camera using the DPController v. 1.1.1.65 software.

To confirm the purity of each meiotic prophase sorted fraction, an aliquot of each classified fraction of $4 \mathrm{C}$ cells (LZ and PS) was immunolabeled with a rabbit antibody raised against the C-terminal region of mouse SYCP3 (Acris Antibodies GmbH, Herford, Germany; RA25051, 1:100) and Texas Red-tagged goat anti-rabbit secondary antibody (Abcam, Cambridge, MA; ab6719, 1:500) as described earlier [19]. Fluorescent images were acquired with the Fluoview v.4.3 software.

\section{RNA extraction and amplification}

Total RNA of each sorted fraction (coming from pooled material from various specimens, as stated above) was extracted with the PureLink RNA Mini Kit (Ambion-Life Technologies, Carlsbad, CA), following the recommendations of the manufacturer. RNA quantitation was performed by fluorometry using Qubit 2.0 and RNA HS Assay (Life Technologies). In general, 50-70 ng total RNA was obtained from $\sim 3 \times 10^{5}$ sorted cells. RNA linear amplification of high purity sorted cells was performed with the Ovation RNA-Seq System v2 (NuGEN, San Carlos, CA), an RNA-based single-primer isothermal amplification (SPIA) technology that has proven to be highly sensitive for whole-transcriptome sequencing using limited amounts of total RNA [43]. RNA amplification was performed following the manufacturer's recommendations. Quality and quantity of the resulting double-stranded cDNA were evaluated by means of a 2100 Bioanalyzer (Agilent, Santa Clara, CA) and Nanodrop 1000 (Thermo Fisher Scientific, Wilmington, DE), respectively.

\section{RNAseq, data processing and analysis}

Libraries were constructed and sequenced at Macrogen (Seoul, Korea), on Illumina HiSeq2000 platform. Quality, length trimming and RNAseq quantification were conducted using CLC Genomics Workbench 6.5 (CLC bio, 
http://www.clcbio.com). Low quality reads $(\mathrm{Q}<33, p \leq$ $0.01)$ and the first 15 bases of the reads with a distinctly non-random base composition were also removed according to [102]. CLC Genomics Workbench 6.5 was used for all data analysis downstream.

High-quality reads for each cell population (2C, LZ, PS, RS) were aligned to the Mus musculus genome GCRm38 assembly from C57BL/6 J strain, using the RNAseq pipeline from CLC bio. Paired-end Illumina RNAseq data were mapped with the following parameters: a) maximum number of allowed mismatches was two; b) minimum length and similarity fraction was set at 0.9 ; and c) minimum number of hits per read was 10 . Gene expression values were reported as RPKM, as described by Mortazavi et al. [103].

In order to ensure comparability, RPKM values were normalized by quantile method implemented in CLC bio. A gene was considered as expressed if it had more than 10 aligned reads and $R P K M \geq 2$. Differential gene expression between the four testicular cell populations was obtained by pairwise comparisons in chronological order of appearance along the first spermatogenic wave (2C vs LZ; LZ vs PS; PS vs RS). An absolute FC of 2 was used to filter the DEG. The $p$ value cut-off was set at $p \leq 0.01$ based on Kal's Z test statistical analysis [104].

The obtained results were also analyzed using a different pipeline to verify the general output of CLC pathway. Reads that passed quality control for each cell population were aligned to the mouse genome by TopHat 2.0.4 [105]. Aligned reads were counted by HTSeq 0.6.0 [106], and differential gene expression analyses were performed with edgeR 3.2.4 [107, 108]. The biological coefficient of variation (BCV) was set manually at 0.4 as recommended in user guides for no replicates.

Based on the differential gene expression analysis among the four cell populations, we used STEM (Short Time series Expression Miner, http://www.sb.cs.cmu.edu/stem/) in order to cluster gene expression patterns in short time series. The input data file contains the time series of gene expression values (RPKM). We selected the Stem Clustering Methods based on units of change (c) defined as $c=2$. Basically, if $\mathrm{c}=2$ between successive time points, a gene can go up either one or two units, stay unchanged, or go down one or two units. From these possible expression profiles, a set of candidate profiles $(\mathrm{m})$ defined by the user as $m=50$ were organized in such a way that the minimum distance between any two profiles was maximized. Each gene was assigned to the closest profile using a Pearson correlation based on metric distance. To determine a significance level for a given cluster, a permutation-based test was used to quantify the expected number of genes that would be assigned to each profile if the data were randomly generated. Data was considered significantly different at $p$ value $=0.05$.
Webgestalt (http://bioinfo.vanderbilt.edu/webgestalt/) and David Bioinformatics Resources 6.7 (http:// david.ncifcrf.gov/) were used for functional enrichment analysis of the differentially expressed filtered gene lists toward KEGG pathways and GO categories. Heat maps and barplots comparing the differential gene expression and enrichment of GO categories were produced with $\mathrm{R}$ bioconductor (http://cran.r-project.org/). Color gradient from red to yellow in the barplots corresponds to increasing $p$-values: red indicates low $p$ values (high enrichment), while yellow indicates high $p$-values (low enrichment). Analyses of top canonical pathways and molecular and cellular functions were performed with QIAGEN's Ingenuity Pathway Analysis (www.qiagen.com/ingenuity).

For heat maps representing the expression levels of genes located on the $\mathrm{X}$ chromosome, a list of X-linked protein-coding genes was obtained from Ensembl Biomart search engine (http://www.ensembl.org/biomart/), combined with our RNAseq data for the four populations, and represented graphically through $\mathrm{R}$ bioconductor as mentioned above. To determine whether DEG had preferential chromosome location, hypergeometric tests were performed in $\mathrm{R}$ bioconductor and enrichment/depletion $p$-values were calculated.

\section{Confirmative qRT-PCR}

For confirmative qRT-PCR assays, cells (2C, LZ, PS, and $\mathrm{RS}$ ) were sorted from the same regions determined on VDG fluorescence intensity and FSC-H as described above. The number of collected cells was assessed by employing the CloneCyt Plus software (BD) in the Counter mode, and 3,000 cells were assayed in each reaction. Cell lysates were used for RT-PCR by means of the Power SYBR Green Cells-to-Ct Kit (Ambion-Life Technologies) essentially as instructed, using random primers. For the real-time PCR step we used $4 \mu \mathrm{L}$ cDNA in a $25 \mu \mathrm{L}$ reaction mix, according to the manufacturer's instructions. All the reactions were performed in three biological replicas in a CFX96 Touch Real-Time PCR Detection System1 (BioRad, Hercules, CA). Ppp1cc (protein phosphatase 1, catalytic subunit, gamma isozyme) and Tax1bp1 (human T-cell leukemia virus type I-binding protein 1) were chosen as control genes both because they were in a list of Applied Biosystem's TaqMan endogenous controls and in a list of housekeeping genes from previous papers [60, 61]. Besides, in our RNAseq results they exhibited similar expression levels in the four assayed testicular cell populations (see Additional file 2: Dataset S1). The genes selected for confirmation by qRT-PCR are shown in Fig. 6, and all especially designed primers are listed in Additional file 1: Table S2.

Amplification efficiency was evaluated via standard curve analysis, and was $>93 \%$. The average threshold cycle $(\mathrm{Ct})$ 
was calculated for each sample using the $2^{-\Delta \Delta C t}$ method normalized to Ppp1cc, and the results were cross-validated with Tax1bp1.

\section{Ethics approval}

All animal procedures were performed following the recommendations of the Uruguayan National Commission of Animal Experimentation (CNEA, approved experimental protocol 001/02/2012). Animal housing and breeding at IIBCE was approved by CNEA (code: 008/11; http://www.cnea.org.uy/index.php/instituciones/registro/10).

\section{Consent for publication \\ Not applicable.}

\section{Availability of data and materials}

The data sets supporting the results of this article are available at the Sequence Read Archive repository, Project ID: PRJNA317251.

\section{Additional files}

Additional file 1: Figure S1. Testicular cell content evaluation in pre-pubertal mice. A. Epon-embedded cross sections of seminiferous tubules in 10-13 dpp pups, stained with toluidine blue. Bar: $50 \mu \mathrm{m}$. B. Analysis of meiotic prophase stages by confocal immunocytochemistry with anti-SYCP3 antibody (green) in whole testicular cell suspensions of 10-12 dpp pups. L, Z and P spermatocyte nuclei are indicated. ItZ: late zygotene. Bar: $10 \mu \mathrm{m}$. Figure S2. Enrichment analysis of biological process GO terms of genes showing an expression peak in LZ. Table S1. Sequencing yield of individual samples. Table S2. List of primers used for qRT-PCR in this study. (PDF $238 \mathrm{~kb}$ )

Additional file 2: Dataset S1. Lists of genes and their normalized expression values in mouse 2C, LZ, PS, and RS testicular cell populations. (XLSX $570 \mathrm{~kb})$

Additional file 3: Dataset S2. Top five canonical pathways and molecular and cellular functions from pairwise comparisons of the four cell populations in chronological order (LZ relative to 2C; PS relative to LZ; RS relative to $P S)$. (XLSX $10 \mathrm{~kb}$ )

Additional file 4: Dataset S3. List of X-linked genes showing a 5- to 1000-fold increase from LZ to PS. (XLSX $10 \mathrm{~kb}$ )

Additional file 5: Dataset S4. Comparison of the RNAseq data generated in this work with the protein data reported by Gan et al. (2013) [69] for their cluster 4, which comprises proteins more abundant during spermiogenesis (RS and elongating spermatids) than in earlier stages. For both data sets $2 \mathrm{C}$ population was taken as a reference, and RNA as well as protein ratios (RATIO and $\mathrm{RATIO}_{\mathrm{p}}$, respectively) between the analyzed cell populations were calculated accordingly. The quantitative relationship between RNA and protein levels was determined at the transitions 2C-PS and PS-RS (RATIO $m p=$ RATIO $/$ RATIO $)$. As in Gan's report, $\mathrm{RATIO} \mathrm{mp}_{\mathrm{m}} \geq 2$ at the 2 C/PS transition was interpreted as translational repression, while $\mathrm{RATIO}_{\mathrm{mp}} \leq 0.5$ at the PS/RS transition was assigned to translational de-repression. Red crosses (right column) indicate the transcripts within this group that would be translationally repressed during PS and de-repressed later on at RS. (XLSX $65 \mathrm{~kb}$ )

\section{Abbreviations}

DEG: differentially expressed genes; dpp: days postpartum; FACS: fluorescenceactivated cell sorting; FC: fold change; FCM: flow cytometry; FL1-A: pulse-area or total emitted fluorescence; FL1-W: pulse-width or duration of fluorescence emission; FSC-H: forward scatter; GES: gene expression signatures; GO: gene ontology; L: leptotene; LZ: lepto/zygotene; MSCl: meiotic sex chromosome inactivation; NGS: next generation sequencing; P: pachytene; PRM: protamine; PS: pachytene spermatocytes; RPKM: reads per kilobase per million mapped reads; RS: round spermatids; SSC-H: side scatter; TNP: transition protein; VDG: Vybrant DyeCycle Green; Z: zygotene.

\section{Competing interests}

The authors declare that they have no competing interests.

\section{Authors' contributions}

Conceived the idea: RB, AG. Performed wet lab experiments: RRC, FFS, GC, CAC. Design of RNA-seq: JRSS. Bioinformatic analysis: IdC, JF, RRC, JRSS. Data analysis: RRC, AG. Interpretation of results: IdC, RRC, GF, RB, JRSS, AG. Wrote the manuscript: AG. Helped writing the manuscript: IdC, GF, RB, RRC, JRSS. All authors read and approved the final manuscript. IdC and RRC share first authorship.

\section{Author's information}

Instituto de Investigaciones Biológicas Clemente Estable (IIBCE), Av. Italia 3318.11,600 Montevideo, Uruguay.

\section{Acknowledgements}

The authors would like to thank the staff of the animal facility at IIBCE for their careful tracking of delivery dates.

\section{Funding}

This work was supported by Agencia Nacional de Investigación e Innovación (ANII, Uruguay) (Project No FCE-1-2011-1-6742 to A.Geisinger), including the research contract of I. da Cruz.

\section{Author details}

'Department of Genomics, Instituto de Investigaciones Biológicas Clemente Estable (IIBCE), Av. Italia 3318, 11,600 Montevideo, Uruguay. ${ }^{2}$ Department of Molecular Biology, Instituto de Investigaciones Biológicas Clemente Estable (IIBCE), Av. Italia 3318, 11,600 Montevideo, Uruguay. ${ }^{3}$ Flow Cytometry and Cell Sorting Core, IIBCE, Montevideo, Uruguay. ${ }^{4}$ Department of Proteins and Nucleic Acids, IIBCE, Montevideo, Uruguay. ${ }^{5}$ Department of Genetics, IIBCE, Montevideo, Uruguay. ${ }^{6}$ Department of Cell and Developmental Biology, Biocenter, University of Würzburg, D-97074 Würzburg, Germany. ${ }^{7}$ Department of Cell and Molecular Biology, Facultad de Ciencias, Universidad de la República (UDELAR), 11,400 Montevideo, Uruguay. ${ }^{8}$ Biochemistry-Molecular Biology, Facultad de Ciencias, UDELAR, Montevideo, Uruguay.

Received: 3 October 2015 Accepted: 13 April 2016

Published online: 19 April 2016

\section{References}

1. Höög C. Expression of a large number of novel testis-specific genes during spermatogenesis coincides with the functional reorganization of the male germ cell. Int J Dev Biol. 1995;39:719-26.

2. Eddy EM. Regulation of gene expression during spermatogenesis. Semin Cell Dev Biol. 1998:9:451-7.

3. Reuter K, Schlatt S, Ehmcke J, Wistuba J. Fact or fiction: In vitro spermatogenesis. Spermatogenesis. 2012;2:245-52.

4. Schultz N, Hamra FK, Garbers DL. A multitude of genes expressed solely in meiotic or postmeiotic spermatogenic cells offers a myriad of contraceptive targets. Proc Natl Acad Sci U S A. 2003;100:12201-6.

5. Almstrup K, Nielsen JE, Hansen MA, Tanaka M, Skakkebaek NE, et al. Analysis of cell-type-specific gene expression during mouse spermatogenesis. Biol Reprod. 2004;70:1751-61.

6. Maratou K, Forster T, Costa Y, Taggart M, Speed RM, et al. Expression profiling of the developing testis in wild-type and Dazl knockout mice. Mol Reprod Dev. 2004:67:26-54

7. Shima JE, McLean DJ, McCarrey JR, Griswold MD. The murine testicular transcriptome: Characterizing gene expression in the testis during the progression of spermatogenesis. Biol Reprod. 2004;71:319-30.

8. Iguchi N, Tobias JW, Hecht NB. Expression profiling reveals meiotic male germ cell mRNAs that are translationally up- and down-regulated. Proc Natl Acad Sci U S A. 2006;103:7712-17.

9. Xiao P, Tang A, Yu Z, Gui Y, Cai Z. Gene expression profile of 2058 spermatogenesis-related genes in mice. Biol Pharm Bull. 2008;31:201-6. 
10. Waldman Ben-Asher H, Shahar I, Yitzchak A, Mehr R, Don J. Expression and chromosomal organization of mouse meiotic genes. Mol Reprod Dev. 2010; 77:241-8.

11. Laiho A, Kotaja N, Gyenesei A, Sironen A. Transcriptome profiling of the murine testis during the first wave of spermatogenesis. PLoS One. 2013;8, e61558.

12. Getun IV, Torres B, Bois PR. Flow cytometry purification of mouse meiotic cells. J Vis Exp. 2011;50:2602.

13. Lam DMK, Furrer R, Bruce WR. The separation, physical characterization, and differentiation kinetics of spermatogonial cells of the mouse. Proc Natl Acad Sci U S A. 1970;65:192-9.

14. Go VLW, Vernon RG, Fritz IB. Studies on spermatogenesis in rats. I. Application of the sedimentation velocity technique to an investigation of spermatogenesis. Can J Biochem. 1971;49:753-60.

15. Romrell $\amalg$, Bellvé $A R$, Fawcet DW. Separation of mouse spermatogenic cells by sedimentation velocity. Dev Biol. 1976;19:119-31.

16. Meistrich ML. Separation of spermatogenic cells and nuclei from rodent testes. Methods Cell Biol. 1977:15:15-54.

17. Malkov M, Fisher Y, Don J. Developmental schedule of the postnatal rat testis determined by flow cytometry. Biol Reprod. 1998:59:84-92.

18. Bastos H, Lassalle B, Chicheportiche A, Riou L, Testart J, et al. Flow cytometric characterization of viable meiotic and postmeiotic cells by Hoechst 33342 in mouse spermatogenesis. Cytometry A. 2005;65:40-9.

19. Rodríguez-Casuriaga R, Geisinger A, Santiñaque F, López B, Folle G. High-purity flow sorting of early meiocytes based on DNA analysis of guinea pig spermatogenic cells. Cytometry A. 2011;79A:625-34.

20. Gaysinskaya V, Soh IY, van der Heijden GW, Bortvin A. Optimized flow cytometry isolation of murine spermatocytes. Cytometry A. 2014;85:556-65.

21. Kotaja N, Kimmins S, Brancorsini S, Hentsch D, Vonesch JL, et al. Preparation, isolation and characterization of stage-specific spermatogenic cells for cellular and molecular analysis. Nat Methods. 2004;1:249-54.

22. Sluka P, O'Donnell L, McLachlan RI, Stanton PG. Application of laser-capture microdissection to analysis of gene expression in the testis. Prog Histochem Cytochem. 2008:42:173-201.

23. Johnston DS, Wright WW, Dicandeloro P, Wilson E, Kopf GS, et al. Stage-specific gene expression is a fundamental characteristic of rat spermatogenic cells and Sertoli cells. Proc Natl Acad Sci U S A. 2008;10524:8315-20.

24. Handel MA, Schimenti JC. Genetics of mammalian meiosis: regulation, dynamics and impact on fertility. Nat Rev Genet. 2005:11:124-36.

25. Hunt PA. Meiosis in mammals: Recombination, non-disjunction and the environment. Biochem Soc Transact. 2006:34:574-7.

26. Scherthan $\mathrm{H}$. Telomere attachment and clustering during meiosis. Cell Mol Life Sci. 2007;64:117-24.

27. Rodríguez-Casuriaga R, Santiñaque FF, Folle GA, Souza E, López-Carro B, et al. Rapid preparation of rodent testicular cell suspensions and spermatogenic stages purification by flow cytometry using a novel blue laser-excitable vital dye. Methods X. 2014;1:239-43.

28. Geisinger A, Rodríguez-Casuriaga R. Flow Cytometry for Gene Expression Studies in Mammalian Spermatogenesis. Cytogenet Genome Res. 2010;128:46-56.

29. Rodríguez-Casuriaga R, Geisinger A, López-Carro B, Porro V, Wettstein R, et al. Ultra-fast and optimized method for the preparation of rodent testicular cells for flow cytometric analysis. Biol Proced Online. 2009;11:184-95.

30. Rodríguez-Casuriaga R, Folle GA, Santiñaque F, López-Carro B, Geisinger A. Simple and efficient technique for the preparation of testicular cell suspensions. J Vis Exp. 2013;78, e50102.

31. Yu Z, Guo R, Ge Y, Ma J, Guan J, et al. Gene expression profiles in different stages of mouse spermatogenic cells. Biol Reprod. 2003;69:37-47.

32. Rossi P, Dolci S, Sette C, Capolunghi F, Pellegrini M, et al. Analysis of the gene expression profile of mouse male meiotic germ cells. Gene Expr Patterns. 2004;4:267-81.

33. Schlecht U, Demougin P, Koch R, Hermida L, Wiederkehr C, et al. Expression profiling of mammalian male meiosis and gametogenesis identifies novel candidate genes for roles in the regulation of fertility. Molec Biol Cell. 2004;15:1031-43.

34. Pang AL, Johnson W, Ravindranath $\mathrm{N}$, Dym M, Rennert OM, et al. Expression profiling of purified male germ cells: stage-specific expression patterns related to meiosis and postmeiotic development. Physiol Genomics. 2006;24:75-85.

35. Fallahi M, Getun IV, Wu ZK, Bois PRJ. A Global Expression Switch Marks Pachytene Initiation during Mouse Male Meiosis. Genes. 2010;1:469-83.

36. Xu Q, Modrek B, Lee C. Genome-wide detection of tissue-specific alternative splicing in the human transcriptome. Nucleic Acids Res. 2002;30:3754-66.
37. Huang X, Li J, Lu L, Xu M, Xiao J, et al. Novel development-related alternative splices in human testis identified by cDNA microarrays. J Androl. 2005;26:189-96.

38. Soumillon M, Necsulea A, Weier M, Brawand D, Zhang X, et al. Cellular source and mechanisms of high transcriptome complexity in the mammalian testis. Cell Rep. 2013;3:2179-90.

39. Margolin G, Khil PP, Kim J, Bellani MA, Camerini-Otero RD. Integrated transcriptome analysis of mouse spermatogenesis. BMC Genomics. 2014;15:39.

40. Hammoud SS, Low DH, Yi C, Carrell DT, Guccione E, et al. Chromatin and transcription transitions of mammalian adult germline stem cells and spermatogenesis. Cell Stem Cell. 2014;15:239-53.

41. Chalmel F, Lardenois A, Evrard B, Rolland AD, Sallou O, et al. High-resolution profiling of novel transcribed regions during rat spermatogenesis. Biol Reprod. 2014;91:5.

42. Modzelewski AJ, Holmes RJ, Hilz S, Grimson A, Cohen PE. AGO4 regulates entry into meiosis and influences silencing of sex chromosomes in the male mouse germline. Dev Cell. 2012;23:251-64.

43. Tariq MA, Kim HJ, Jejelowo O, Pourmand N. Whole-transcriptome RNAseq analysis from minute amount of total RNA. Nucleic Acids Res. 2011;39, e120.

44. Bolcun-Filas E, Schimenti JC. Genetics of meiosis and recombination in mice. Int Rev Cell Mol Biol. 2012;298:179-227.

45. Cobb J, Miyaike M, Kikuchi A, Handel MA. Meiotic events at the centromeric heterochromatin: histone $\mathrm{H} 3$ phosphorylation, topoisomerase II alpha localization and chromosome condensation. Chromosoma. 1999:108:412-25.

46. Luo M, Zhou J, Leu NA, Abreu CM, Wang J, et al. Polycomb protein SCML2 associates with USP7 and counteracts histone H2A ubiquitination in the XY chromatin during male meiosis. PLoS Genet. 2015;11, e1004954.

47. Naaby-Hansen S, Herr JC. Heat shock proteins on the human sperm surface. J Reprod Immunol. 2010;84:32-40.

48. Shen CC, Kang YH, Yu L, Cui DD, He Y, et al. Human testis-expressed sequence 101 is limitedly distributed in germinal epithelium of testis and disappears in seminoma. Biol Res. 2014;47:52.

49. Yoshitake $H$, Yanagida M, Maruyama M, Takamori K, Hasegawa A, et al. Molecular characterization and expression of dipeptidase 3, a testis-specific membrane-bound dipeptidase: complex formation with TEX101, a germcell-specific antigen in the mouse testis. J Reprod Immunol. 2011;90:202-13.

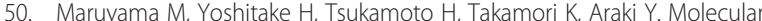
expression of Ly6k, a putative glycosylphosphatidyl-inositol-anchored membrane protein on the mouse testicular germ cells. Biochem Biophys Res Commun. 2010;402:75-81.

51. Li W, Guo XJ, Teng F, Hou XJ, Lv Z, et al. Tex101 is essential for male fertility by affecting sperm migration into the oviduct in mice. J Mol Cell Biol. 2013;5:345-7.

52. Fujihara Y, Okabe M, Ikawa M. GPI-anchored protein complex, LY6KTEX101, is required for sperm migration into the oviduct and male fertility in mice. Biol Reprod. 2014;90:60.

53. Inoue N, Yamaguchi R, Ikawa M, Okabe M. Sperm-egg interaction and gene manipulated animals. Soc Reprod Fertil Suppl. 2007;65:363-71.

54. Goldberg E, Eddy EM, Duan C, Odet F. LDHC: the ultimate testis-specific gene. J Androl. 2010;31:86-94.

55. Fossella J, Samant SA, Silver LM, King SM, Vaughan KT, et al. An axonemal dynein at the Hybrid Sterility 6 locus: implications for t haplotype-specific male sterility and the evolution of species barriers. Mamm Genome. 2000; 11:8-15.

56. Gong EY, Park E, Lee HJ, Lee K. Expression of Atp8b3 in murine testis and its characterization as a testis specific P-type ATPase. Reproduction. 2009;137: 345-51.

57. Chiriva-Internati M, Gagliano N, Donetti E, Costa F, Grizzi F, et al. Sperm protein 17 is expressed in the sperm fibrous sheath. J Transl Med. 2009;7:61.

58. Kleene $\mathrm{KC}$. A possible meiotic function of the peculiar patterns of gene expression in mammalian spermatogenic cells. Mech Dev. 2001;106:3-23.

59. Braun RE. Post-transcriptional control of gene expression during spermatogenesis. Semin Cell Dev Biol. 1998;9:483-9.

60. Warrington JA, Nair A, Mahadevappa M, Tsyganskaya M. Comparison of human adult and fetal expression and identification of 535 housekeeping/ maintenance genes. Physiol Genomics. 2000;2:143-7.

61. Ersland KM, Christoforou A, Stansberg C, Espeseth T, Mattheisen M, et al. Gene-based analysis of regionally enriched cortical genes in GWAS data sets of cognitive traits and psychiatric disorders. PLoS One. 2012;7, e31687.

62. Alcivar AA, Trasler JM, Hake LE, Salehi-Ashtiani K, Goldberg E, et al. DNA methylation and expression of the genes coding for lactate dehydrogenases $\mathrm{A}$ and $\mathrm{C}$ during rodent spermatogenesis. Biol Reprod. 1991;44:527-35. 
63. Watanabe D, Yamada K, Nishina Y, Tajima Y, Koshimizu U, et al. Molecular cloning of a novel $\mathrm{Ca}(2+)$-binding protein (calmegin) specifically expressed during male meiotic germ cell development. J Biol Chem. 1994;269:7744-9.

64. Wang PJ, McCarrey JR, Yang F, Page DC. An abundance of X-linked genes expressed in spermatogonia. Nat Genet. 2001;27:422-6.

65. Khil PP, Smirnova NA, Romanienko PJ, Camerini-Otero RD. The mouse $X$ chromosome is enriched for sex-biased genes not subject to selection by meiotic sex chromosome inactivation. Nat Genet. 2004;36:642-6.

66. Checchi PM, Engebrecht J. Heteromorphic sex chromosomes: navigating meiosis without a homologous partner. Mol Reprod Dev. 2011;78:623-32.

67. Miki K, Willis WD, Brown PR, Goulding EH, Fulcher KD, et al. Targeted disruption of the Akap4 gene causes defects in sperm flagellum and motility. Dev Biol. 2002;248:331-42.

68. Kitamura K, Iguchi N, Kaneko Y, Tanaka H, Nishimune Y. Characterization of a novel postacrosomal perinuclear theca-specific protein, CYPT1. Biol Reprod. 2004;71:1927-35

69. Gan H, Cai T, Lin X, Wu Y, Wang X, et al. Integrative proteomic and transcriptomic analyses reveal multiple post-transcriptional regulatory mechanisms of mouse spermatogenesis. Mol Cell Proteomics. 2013;12:1144-57.

70. Marguerat S, Bähler J. RNA-seq: from technology to biology. Cell Mol Life Sci. 2010;67:569-79.

71. Idler RK, Yan W. Control of messenger RNA fate by RNA-binding proteins: an emphasis on mammalian spermatogenesis. J Androl. 2012;33:309-37.

72. Lee $\mathrm{K}$, Haugen HS, Clegg CH, Braun RE. Premature translation of protamine 1 mRNA causes precocious nuclear condensation and arrests spermatid differentiation in mice. Proc Natl Acad Sci U S A. 1995;92:12451-5.

73. Elliott D. Pathways of post-transcriptional gene regulation in mammalian germ cell development. Cytogenet Genome Res. 2003;103:210-6.

74. Cullinane DL, Chowdhury TA, Kleene KC. Mechanisms of translational repression of the Smcp mRNA in round spermatids. Reproduction. 2015;149:43-54.

75. Chowdhury TA, Kleene KC. Identification of potential regulatory elements in the $5^{\prime}$ and $3^{\prime}$ UTRs of 12 translationally regulated mRNAs in mammalian spermatids by comparative genomics. J Androl. 2012;33:244-56.

76. Yadav RP, Kotaja N. Small RNAs in spermatogenesis. Mol Cell Endocrinol. 2014;382:498-508.

77. Bao J, Wu J, Schuster AS, Hennig GW, Yan W. Expression profiling reveals developmentally regulated IncRNA repertoire in the mouse male germline. Biol Reprod. 2013;89:107.

78. Meikar O, Vagin W, Chalmel F, Sõstar K, Lardenois A, et al. An atlas of chromatoid body components. RNA. 2014:20:483-95.

79. McCarrey JR, Berg WM, Paragioudakis SJ, Zhang PL, Dilworth DD, et al. Differential transcription of Pgk genes during spermatogenesis in the mouse. Dev Biol. 1992;154:160-8.

80. Yoshioka H, Geyer CB, Hornecker JL, Patel KT, McCarrey JR. In vivo analysis of developmentally and evolutionarily dynamic protein-DNA interactions regulating transcription of the Pgk2 gene during mammalian spermatogenesis. Mol Cell Biol. 2007;27:7871-85.

81. Kleene KC, Distel RJ, Hecht NB. CDNA clones encoding cytoplasmic poly (A) + RNAs which first appear at detectable levels in haploid phases of spermatogenesis in the mouse. Dev Biol. 1983;98:455-64.

82. Hecht NB, Bower PA, Waters SH, Yelick PC, Distel RJ. Evidence for haploid expression of mouse testicular genes. Exp Cell Res. 1986;164:183-90.

83. Mali P, Sandberg M, Vuorio E, Yelick PC, Hecht NB, et al. Localization of protamine 1 mRNA in different stages of the cycle of the rat seminiferous epithelium. J Cell Biol. 1988;107:407-12.

84. Mali P, Kaipia A, Kangasniemi M, Toppari J, Sandberg M, et al. Stage-specific expression of nucleoprotein mRNAs during rat and mouse spermiogenesis. Reprod Fertil Dev. 1989;1:369-82.

85. Steger K, Pauls K, Klonisch T, Franke FE, Bergmann M. Expression of protamine-1 and -2 mRNA during human spermiogenesis. Mol Hum Reprod. 2000;6:219-25.

86. Kleene KC, Distel RJ, Hecht NB. Translational regulation and deadenylation of a protamine mRNA during spermiogenesis in the mouse. Dev Biol. 1984;105:71-9.

87. Kleene KC. Multiple controls over the efficiency of translation of the mRNAs encoding transition proteins, protamines, and the mitochondrial capsule selenoprotein in late spermatids in mice. Dev Biol. 1993;159:720-31.

88. Kleene KC. Connecting cis-elements and trans-factors with mechanisms of developmental regulation of mRNA translation in meiotic and haploid mammalian spermatogenic cells. Reproduction. 2013;146:R1-19.
89. Tseden K, Topaloglu O, Meinhardt A, Dev A, Adham I, et al. Premature translation of transition protein 2 mRNA causes sperm abnormalities and male infertility. Mol Reprod Dev. 2007;74:273-9.

90. Francis S, Yelumalai S, Jones C, Coward K. Aberrant protamine content in sperm and consequential implications for infertility treatment. Hum Fertil. 2014;17:80-9.

91. latrou K, Spira AW, Dixon GH. Protamine messenger RNA: evidence for early synthesis and accumulation during spermatogenesis in rainbow trout. Dev Biol. 1978;64:82-98.

92. VanGompel MJ, Xu EY. The roles of the DAZ family in spermatogenesis: More than just translation? Spermatogenesis. 2011;1:36-46.

93. Niederberger C, Agulnik Al, Cho Y, Lamb D, Bishop CE. In situ hybridization shows that Dazl expression in mouse testis is restricted to premeiotic stages IV-VI of spermatogenesis. Mamm Genome. 1997;8:277-8.

94. Nicholas CR, Xu EY, Banani SF, Hammer RE, Hamra FK, et al. Characterization of a Dazl-GFP germ cell-specific reporter. Genesis. 2009;47:74-84.

95. Reynolds N, Collier B, Maratou K, Bingham V, Speed RM, et al. Dazl binds in vivo to specific transcripts and can regulate the pre-meiotic translation of Mvh in germ cells. Hum Mol Genet. 2005;14:3899-909.

96. Reynolds N, Collier B, Bingham V, Gray NK, Cooke HJ. Translation of the synaptonemal complex component Sycp3 is enhanced in vivo by the germ cell specific regulator Dazl. RNA. 2007;13:974-81.

97. Federici F, Mulugeta E, Schoenmakers S, Wassenaar E, Hoogerbrugge JW, et al. Incomplete meiotic sex chromosome inactivation in the domestic dog. BMC Genomics. 2015;16:291.

98. Song R, Ro S, Michaels JD, Park C, McCarrey JR, et al. Many X-linked microRNAs escape meiotic sex chromosome inactivation. Nat Genet. 2009;41:488-93.

99. Rathke C, Baarends WM, Awe S, Renkawitz-Pohl R. Chromatin dynamics during spermiogenesis. Biochim Biophys Acta. 1839;2014:155-68.

100. Shinagawa T, Huynh LM, Takagi T, Tsukamoto D, Tomaru C, et al. Disruption of Th2a and Th2b genes causes defects in spermatogenesis. Development. 2015;142:1287-92.

101. Govin J, Escoffier E, Rousseaux S, Kuhn L, Ferro M, et al. Pericentric heterochromatin reprogramming by new histone variants during mouse spermiogenesis. J Cell Biol. 2007;176:283-94.

102. Minoche AE, Dohm JC, Himmelbauer H. Evaluation of genomic highthroughput sequencing data generated on Illumina HiSeq and genome analyzer systems. Genome Biol. 2011;12:R112.

103. Mortazavi A, Williams BA, McCue K, Schaeffer L, Wold B. Mapping and quantifying mammalian transcriptomes by RNA-Seq. Nat Methods. 2008;5:621-8.

104. Kal AJ, Van Zonneveld AJ, Benes V, van den Berg M, Koerkamp MG, et al. Dynamics of gene expression revealed by comparison of serial analysis of gene expression transcript profiles from yeast grown on two different carbon sources. Mol Biol Cell. 1999;10:1859-72.

105. Trapnell C, Pachter L, Salzberg SL. TopHat: discovering splice junctions with RNA-Seq. Bioinformatics. 2009;25:1105-11.

106. Anders S, Pyl PT, Huber W. HTSeq- A Python framework to work with highthroughput sequencing data. Bioinformatics. 2015;31:166-9.

107. Robinson MD, Oshlack A. A scaling normalization method for differential expression analysis of RNA-seq data. Genome Biol. 2010;11:R25.

108. Robinson MD, McCarthy DJ, Smyth GK. EdgeR: a Bioconductor package for differential expression analysis of digital gene expression data. Bioinformatics. 2010;26:139-40

\section{Submit your next manuscript to BioMed Central and we will help you at every step:}

- We accept pre-submission inquiries

- Our selector tool helps you to find the most relevant journal

- We provide round the clock customer support

- Convenient online submission

- Thorough peer review

- Inclusion in PubMed and all major indexing services

- Maximum visibility for your research

Submit your manuscript at www.biomedcentral.com/submit 